\title{
L'établissement rural antique du Grand-Herbage à Sées (Orne)
}

Guy Leclerc

\section{(2) OpenEdition}

1 Journals

Édition électronique

URL : https://journals.openedition.org/rao/347

DOI : $10.4000 /$ rao.347

ISBN : 978-2-7535-1607-6

ISSN : $1775-3732$

Éditeur

Presses universitaires de Rennes

Édition imprimée

Date de publication : 30 décembre 2007

Pagination : 139-167

ISBN : 978-2-7535-0574-2

ISSN : 0767-709X

\section{Référence électronique}

Guy Leclerc, «L'établissement rural antique du Grand-Herbage à Sées (Orne) », Revue archéologique de l'Ouest [En ligne], 24 | 2007, mis en ligne le 30 décembre 2009, consulté le 22 août 2022. URL : http:// journals.openedition.org/rao/347 ; DOI : https://doi.org/10.4000/rao.347 


\title{
Létablissement rural antique du Grand-Herbage à Sées (Orne)
}

\author{
Guy LeCLERC*
}

\begin{abstract}
Résumé : L'étude de l'occupation rurale gallo-romaine du Grand-Herbage, à Sées (Orne), a restitué l'organisation d'une entité agricole implantée au $\mathrm{I}^{\text {er }}$ siècle de notre ère, caractérisée par un habitat en dur et par des installations agricoles en matériaux périssables. Suite à son abandon dans la seconde moitié du III $^{\mathrm{e}}$ siècle, l'établissement est réorganisé sous une forme plus modeste.
\end{abstract}

\begin{abstract}
The Antique farmstead of Le Grand-Herbage at Sées (Orne)
The study of the rural occupation of Le Grand-Herbage at Sées (Orne) revealed the organization of an agricultural unit established in the 1st century A.D. and characterized by a stone built residence and lighter agricultural installations of perishable materials. Following its desertion in the second half of the third century, the farmstead is reorganised in a more modest form.
\end{abstract}

Mots clés : Ferme, Haut-Empire, partie résidentielle, hypocauste, aqueduc, puits, chaufournerie, cour fermée, greniers, Antiquité tardive, Argonne.

Key words: Farmstead, High Empire, residential area, hypocaust, aqueduct, well, lime production, closed courtyard, granaries, Late Antiquity, Argonne ware.

L'occupation gallo-romaine du Grand-Herbage est située à $1,5 \mathrm{~km}$ au sud-ouest de la ville de Sées, ancien chef-lieu de cité des Sagiens (fig. 1). Son étude exhaustive a livré l'image d'une exploitation agricole caractérisée par une faible emprise évaluée à $3000 \mathrm{~m}^{2}$ et par la diversité de ses composantes architecturales.

Les vestiges ont été découverts en 1995 dans le cadre d'une opération de prospection-inventaire initiée dans le canton de Sées. La mise au jour, la même année, d'un aqueduc antique en relation apparente avec le site a conforté l'intérêt de ce dernier. Les sondages d'évaluation réalisés en 1999 ont révélé des structures très arasées appartenant à un établissement aux dimensions modestes mais dont le plan d'organisation restait lisible. Une fouille exhaustive de l'occupation a été conduite sur trois campagnes, de 2000 à 2002; elle a livré les éléments appartenant à un habitat résidentiel ainsi que les annexes agricoles réparties dans une cour ${ }^{1}$.

\section{Présentation du Site}

\section{Contexte topographique et géologique}

Dans la plaine sédimentaire de Sées, le site du GrandHerbage occupe le flanc occidental d'un ruisseau qui domine une dépression argileuse alimentant de façon intermittente un petit cours d'eau. Les vestiges sont situés sur une pente moyenne de 4,8\%, à une altitude comprise entre 189 et $193 \mathrm{~m}$.

L'habitat antique a été curieusement établi, non sur le niveau calcaire porteur du plateau, mais sur le versant occidental formé par l'affleurement d'un sable rendant le sol instable et peu propice à la construction. Cette option, qui n'a pas pris en compte les qualités édaphiques du lieu, pourrait se justifier par la nécessité de s'établir à un niveau inférieur à celui de l'aqueduc voisin, de façon à bénéficier d'une alimentation en eau par gravité.

\footnotetext{
* Société historique et archéologique de l'Orne, Alençon.
}

1. Cet article vise à une présentation générale du site et de son mobilier céramique; deux études complémentaires l'accompagnent dans ce même volume : l'une est consacrée au mobilier métallique (par M. Demarest, p. 169-189) et l'autre à celle des restes fauniques (par A. Baudry, p. 191-201). 


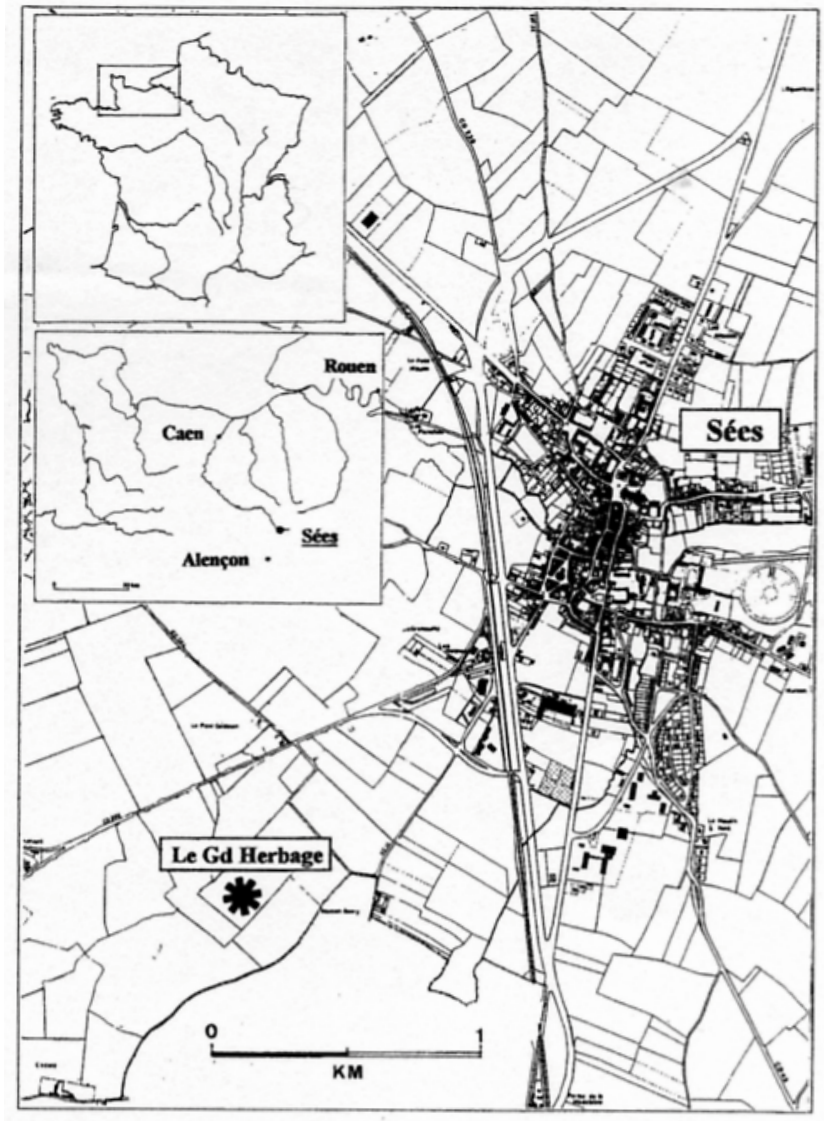

Figure 1 : Sées, Le Grand-Herbage : plan de situation. Figure 1: Location map.

Le démontage du puits installé dans la première cour a précisé ce contexte géologique. Sous le calcaire supérieur érodé, une couche de sable d'une épaisseur de $1,80 \mathrm{~m}$ couvre un banc de calcaire très dur d'une puissance de $1,10 \mathrm{~m}$. L'horizon inférieur est constitué de deux niveaux superposés d'argiles de couleurs bleue et gris-vert, sans doute d'origine liasique et reposant directement sur le socle paléozoïque ou sur ses niveaux détritiques. La nappe phréatique a été atteinte à $-4,70 \mathrm{~m}$ par rapport au niveau de décapage. La présence d'eau et les qualités agronomiques du sol limoneux sur le plateau ont constitué des facteurs favorables à l'implantation d'activités agricoles.

\section{L'organisation rurale de la plaine de Sées}

Le site du Grand-Herbage appartient à la nébuleuse d'occupations rurales antiques mise en évidence autour de la ville de Sées, dans un rayon de 6 à $7 \mathrm{~km}$. Ce cortège d'établissements témoigne d'une activité agricole importante devant assurer l'autosuffisance alimentaire des populations ainsi que l'approvisionnement du marché urbain local. Ces sites ne sont connus que par les données fragmentaires fournies par les prospections de surface récentes. Ils occupent préférentiellement les bords de plateaux, à des altitudes comprises entre 180 et $200 \mathrm{~m}$, à la limite entre des dépressions peu marquées liées aux cours d'eau et des zones plus élevées, alors probablement couvertes de massifs forestiers. De même, en ce qui concerne la nature des sols, plus d'une dizaine d'habitats se situe à la limite séparant les zones limoneuses favorables aux cultures et celles à sols lessivés plus propices à l'élevage. Ainsi, le choix d'implantation du Grand-Herbage et de plusieurs entités agricoles de la plaine de Sées répondrait au souci de s'assurer la maîtrise de plusieurs aires de gestion différenciées.

La présence d'une occupation indigène préexistant à ces implantations antiques commence, depuis peu, à être mise en évidence. Les prospections aériennes n’ont révélé jusqu’à présent qu'un seul site présentant la morphologie des fermes gauloises fossoyées, celui de Boisville à Sées; ce sont surtout les sauvetages archéologiques liés aux travaux autoroutiers qui ont documenté le corpus des établissements agricoles laténiens comme celui de Neuville-près-Sées (BesnardVauterin, 2005).

\section{L'ÉTABLISSEMENT du HAUT-EMPIRE}

\section{L'implantation initiale}

La première occupation (fig. 2) est matérialisée par une unité d'habitation de forme rectangulaire (bâtiment 1), de 15,65 m sur 9,10 m, sans galerie(s) de façade visible(s). Cette construction ne subsiste que par ses fondations puissantes en pierres sèches placées dans une tranchée de section trapézoïdale. Ce radier est constitué d'une armature de gros blocs de grès armoricain ${ }^{2}$ calés avec des pierres de petit module; sa largeur est comprise entre 0,70 et $0,75 \mathrm{~m}$ et son épaisseur, testée sur trois côtés du bâtiment, varie de 0,60 à $0,90 \mathrm{~m}$. La mise en place d'une armature de pierres de gros module dans la fondation se justifie par l'instabilité du substrat sableux qui a commandé ce choix d'aménagement. Sur le plan architectural, cet habitat sans galerie de façade visible est comparable à celui de la $\mathrm{ZAC}$ du Long Buisson à Évreux, dans l'Eure (Carpentier et al., 2004).

La structuration de l'espace intérieur de l'habitation n'est pas perceptible faute de traces de cloisons conservées au sol. De même, aucun niveau de démolition n'a été identifié sur place excepté quelques fragments de torchis. Le seul aménagement visible est un foyer (F 30). Le nettoyage du lieu et la récupération de matériaux dans la seconde moitié du III $^{\mathrm{e}}$ siècle (cf. infra) expliqueraient cette lacune (fig. 3).

2. La formation dite " grès armoricain " est un grès souvent quartziteux, d'âge ordovicien, qui affleure largement au sud-ouest de Sées. 


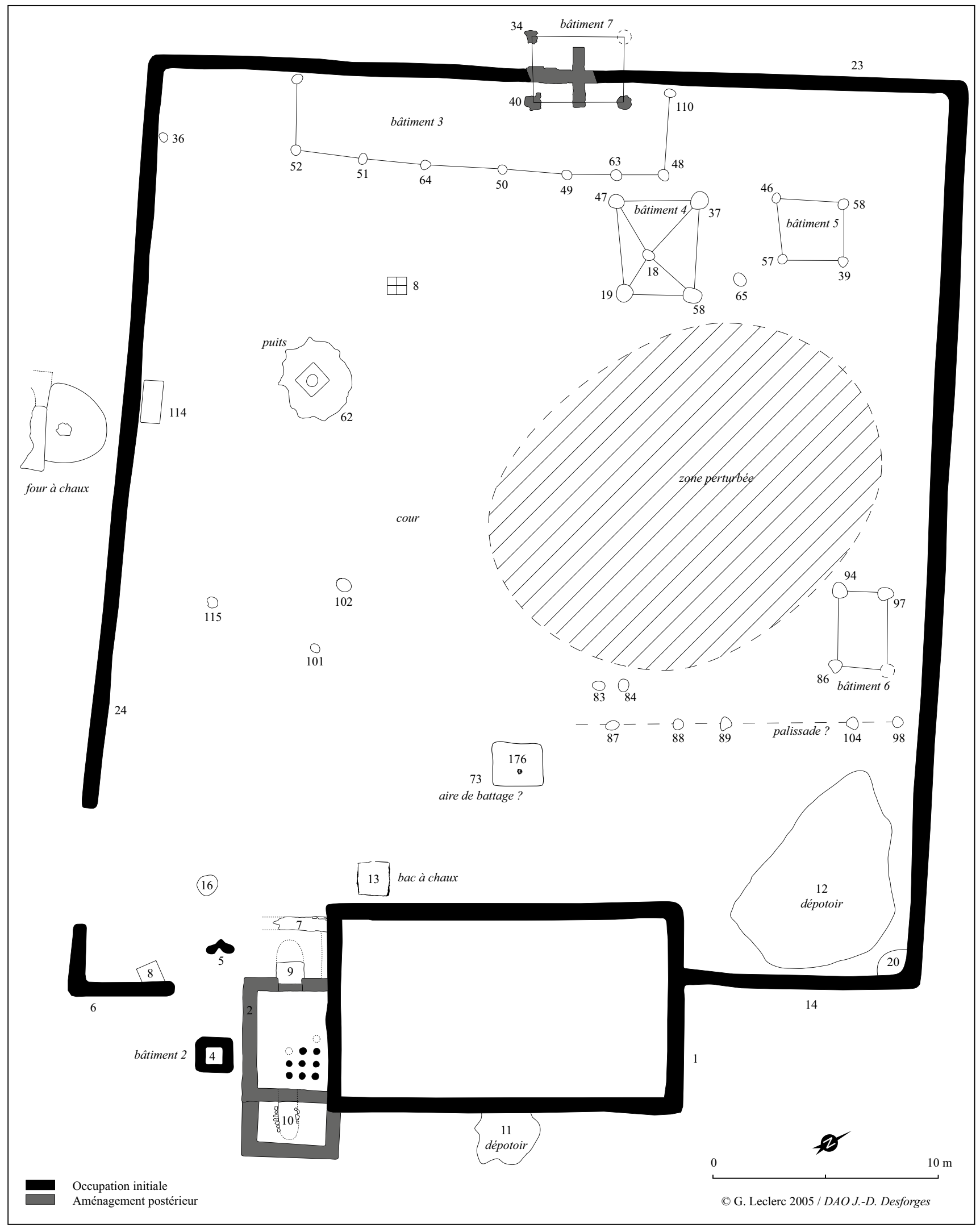

Figure 2 : Sées, Le Grand-Herbage : aménagements du Haut-Empire.

Figure 2: High-Empire layout. 


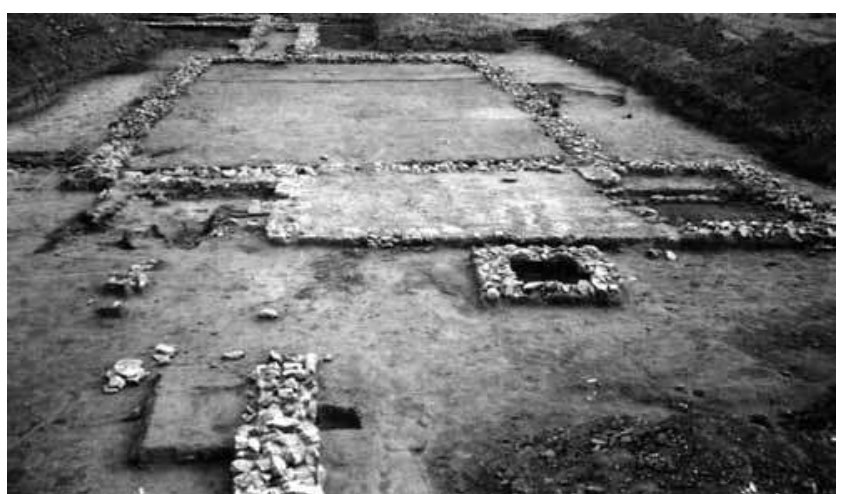

Figure 3 : Le secteur résidentiel vu depuis le sud-ouest.

Figure 3: The residential area seen from south-west.

Cette première implantation est dotée d'une cour quadrangulaire d'une superficie de $1450 \mathrm{~m}^{2}$, fermée par un mur dont le mode de construction est comparable à celui du bâtiment d'habitation exception faite de l'incorporation de pierres sèches calcaires non taillées - parfois associées à des blocs de grès - dans le radier de fondation. Cet espace, de forme légèrement trapézoïdale et dont l'axe est un peu décalé au nord-est, est connecté à l'habitat par ses murs latéraux longs de 40 et $38,20 \mathrm{~m}$. Il est doté d'un porche d'entrée placé face au bâtiment, au milieu du mur de façade nordouest long de $35,80 \mathrm{~m}$. Cette ouverture, large de $3,30 \mathrm{~m}$, était apparemment protégée par un auvent (bâtiment 7) reposant sur quatre poteaux de bois dont le diamètre a pu être évalué à une trentaine de centimètres dans les trois calages conservés (F 34, F 40, F 41). Chronologiquement, cette première phase d'occupation est datable des années 50-80 de notre ère (cf infra, $\$$ chronologie).

\section{L'évolution de l'établissement}

\section{L'extension de l'habitat}

Dans le dernier tiers du $\mathrm{I}^{\mathrm{er}}$ siècle, une évolution tangible intervient sur l'ensemble de l'occupation. Elle est caractérisée par un nouveau mode de construction utilisant des moellons calcaires taillés et liés à la chaux. Cette phase d'aménagement est marquée par une extension du bâtiment résidentiel et par la fermeture du porche d'entrée de la cour, probablement compensée par une ouverture pratiquée au sud-ouest. Elle semble concerner également l'intérieur du bâtiment 1 comme l'attestent les calages en calcaire de trois poteaux (F 31, F 32, F 33), accolés contre la face interne du mur dans l'angle nord de l'habitation.

La nouvelle morphologie de l'habitat prend en compte l'adjonction, contre le mur sud-ouest, d'une pièce rectangulaire sur hypocauste à pilettes d'une surface de $18 \mathrm{~m}^{2}$. Cet aménagement de confort, très arasé, ne subsiste plus que par la fondation de son mur périphérique et par le sol en béton de la chambre de chaleur (fig. 4). Les murs de la pièce, larges de 0,60 m, sont élaborés en petits moellons calcaires appareillés à la chaux dont une seule assise subsiste au-dessus de la fondation, conservée sur une hauteur de 0,36 m. Ils étaient probablement décorés d'un enduit peint à motifs géométriques et figurés (pattes de volatile?) dont les restes très fragmentés ont été retrouvés dans la couche d'abandon. Le sol de l'hypocauste, d'une épaisseur totale de $0,35 \mathrm{~m}$, est formé d'une couche de béton de tuileau épaisse de 5 à $7 \mathrm{~cm}$, reposant sur deux assises de pierres sèches calcaires. Les pilettes de soutènement

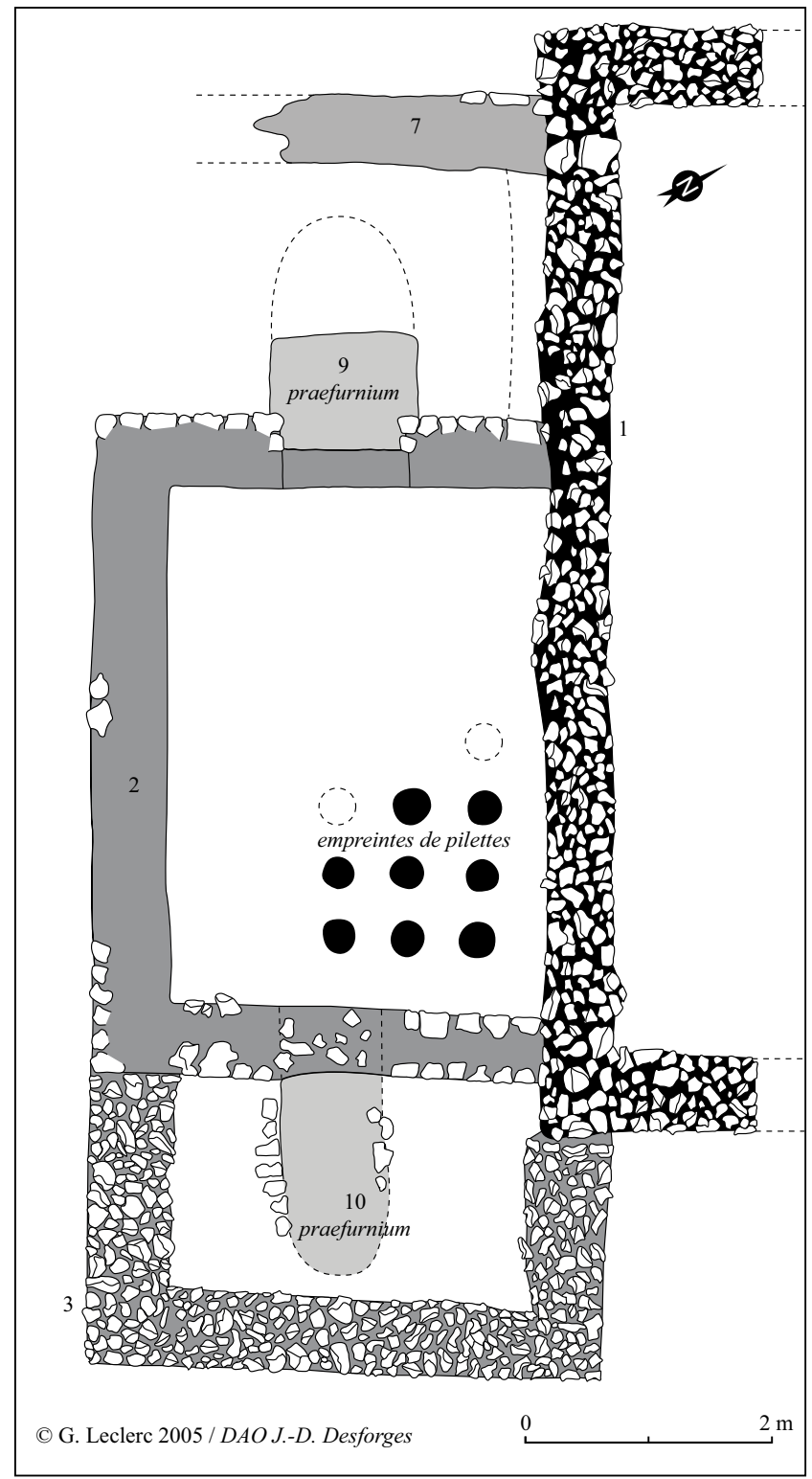

Figure 4 : Planimétrie de l'extension du bâtiment 1 (phase 2) : hypocauste à double praefurnium.

Figure 4: Detailed plan of Building 1, extension (phase 2): hypocaust with double praefurnium. 
ont été arasées; seules, les traces d'arrachement à la surface du sol marquent leur emplacement. Quelques briques de forme carrée en ont été retrouvées dans des niveaux remaniés ${ }^{3}$, de même que des fragments de suspensurae et de tubuli de section carrée, dotés de stries d'accrochage. Les axes des piliers sont distants de $0,57 \mathrm{~m}$.

L'alimentation en air chaud de l'hypocauste était assurée à partir d'un système de chauffe installé au nord-ouest de la pièce dans un petit local de service délimité par un mur, comme semble l'attester un lambeau de fondation en petits moellons calcaires calibrés. Le praefurnium est pourvu d'un foyer rectangulaire (F 9), de 1,20 m sur $1 \mathrm{~m}$. La sole, de construction soignée, est constituée de plusieurs couches de tegulae (ou de briques à encoche ${ }^{4}$ ) séparées par des lits d'argile crue reposant sur une assise dont ne subsiste qu'une fondation de pierres sèches taillées (fig. 5). Le foyer est précédé d'une couche cendreuse épaisse de $5 \mathrm{~cm}$ reposant sur un niveau de sable et de limon. Il est placé en position extérieure par rapport à la chambre de chaleur avec laquelle il communique par une simple ouverture appareillée aménagée dans le mur de la pièce. Aucun conduit intérieur n'a été repéré dans l'hypocauste.

Une modification du système de chauffe intervient postérieurement. Elle est caractérisée par l'installation d'un second praefurnium côté sud-est, à l'opposé du premier. Un nouveau foyer, F 10 , est placé dans un appentis rectangulaire de $3 \mathrm{~m}$ sur 2, limité par un mur repéré sur trois côtés (fig. 4; fig. 6). Le fourneau, de 1,40 m sur 0,80 m, est également implanté à l'extérieur de la chambre de chauffe. Il se présente sous la forme d'un canal dont le fond a été réalisé avec une couche unique de tegulae et dont les deux côtés sont constitués de murets de pierres sèches de petit calibre, présentant des traces de rubéfaction sur leurs parois intérieures. Il communique avec la chambre de chaleur par un trou pratiqué dans le mur, qui porte des traces d'arrachement de l'appareil initial.

La présence de deux praefurnia pose le problème de leur fonctionnement synchrone ou de l'arrêt du premier pour des raisons indéterminées. Une autre hypothèse est envisageable; le deuxième fourneau constituerait un chauffage d'appoint utilisable, par exemple, lors des périodes les plus froides comme le suggère $F$. Kretzschmer pour les thermes de Timgad (Degbomont, 1984, p. 61-66). Il n'en demeure pas moins qu'au Grand-Herbage, les deux systèmes en position opposée pouvaient difficilement fonctionner simultanément pour des problèmes de tirage, à moins d'envisager une sépa-

3. Ces éléments de pilettes mesurent $19,5 \mathrm{~cm}$ de côté pour une épaisseur de 3,8 cm. Des exemplaires identiques ont été retrouvés sur le site proche du Hamel à Sées (Leclerc 1999, p. 47).

4. Ces briques à encoche (ou à poignée) présentent les caractéristiques suivantes : L. $34,8 \mathrm{~cm}, 1.28,5 \mathrm{~cm}$, ép. $3,2 \mathrm{~cm}$, poids $4,59 \mathrm{~kg}$.

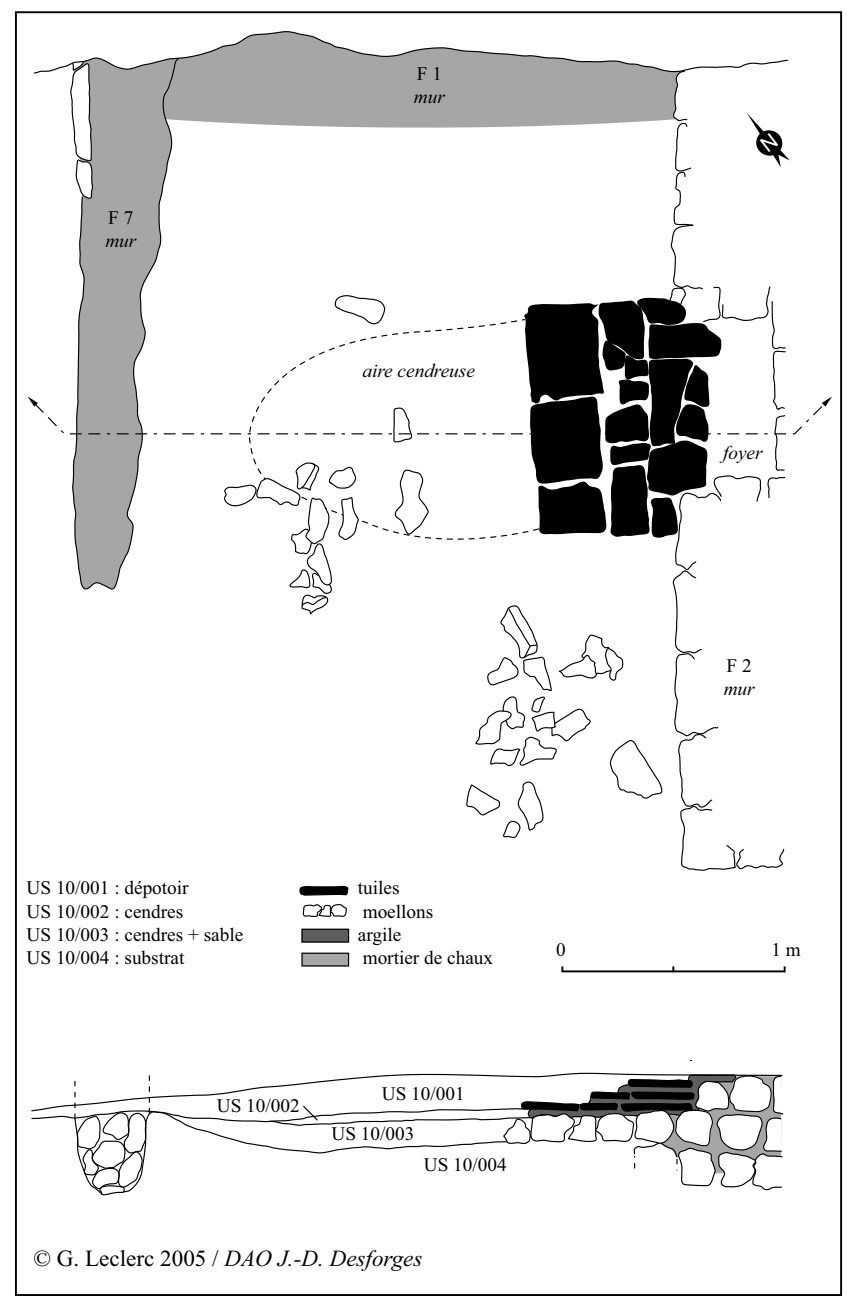

Figure 5 : Planimétrie et coupe stratigraphique du praefurnium $\mathrm{F} 9$. Figure 5: Detailed plan and stratigraphic section of Praefurnium F9.

ration de la chambre de chaleur en deux parties indépendantes - ce que la fouille n'a pas validé - ou un fonctionnement alternatif des foyers en fonction de l'orientation du vent avec un système de fermeture de la bouche inutilisée.

L'extension de l'habitation s'accompagne d'un réaménagement partiel de la cour. Le porche d'entrée est obturé par une maçonnerie appareillée de pierres calcaires taillées et liées à la chaux (fig. 7). Une à deux assises de petits moellons calibrés sont posées sur une semelle débordante visible sous le parement extérieur. Cet ouvrage de condamnation a été conforté par deux murets opposés, longs de $1,05 \mathrm{~m}$, non harpés et d'architecture similaire. L'abandon de cet accès à la cour suppose la création d'une nouvelle entrée, qui a peut-être été pratiquée près de l'angle sud-ouest du bâtiment résidentiel où deux interruptions du mur de cour ont été mises en évidence dans un secteur toutefois très remanié et chronologiquement peu lisible. 


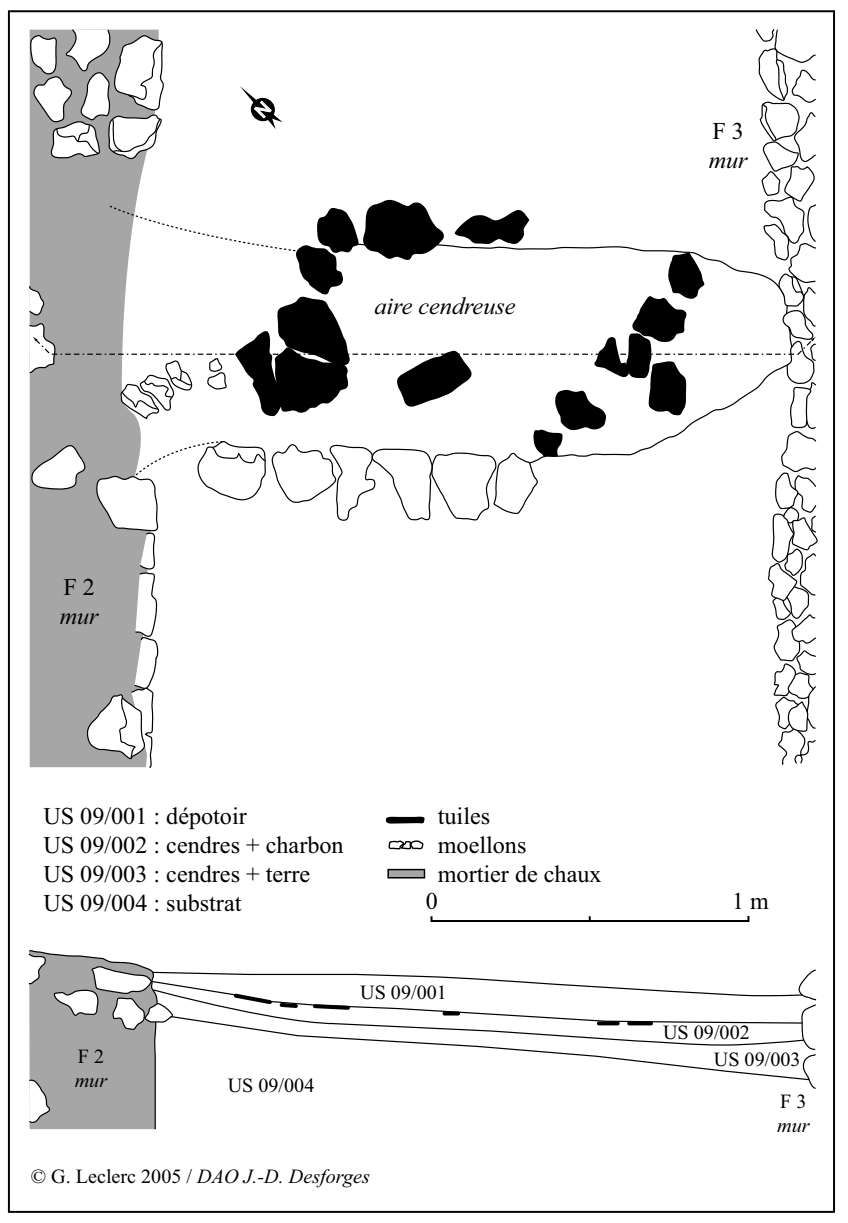

Figure 6 : Planimétrie et coupe stratigraphique du praefurnium F 10. Figure 6: Detailed plan and stratigraphic section of Praefurnium F 10.

\section{Les structures annexes}

Quelques aménagements liés à la construction ou au fonctionnement de l'habitat ont été mis au jour (fig. 2).

- Le bâtiment 2. Une petite structure carrée, contemporaine de la pièce sur hypocauste dont elle reprend l'orientation, a été implantée au sud-ouest du bâtiment principal dont elle n'est distante que de $0,40 \mathrm{~m}$. D'une surface intérieure de $0,70 \mathrm{~m}^{2}$, elle ne subsiste que par un radier de pierres sèches calcaires. Son dégagement jusqu'au substrat sableux n’a révélé aucun niveau anthropique et sa fonction reste hypothétique. Elle a été interprétée comme un petit bâtiment cultuel par comparaison avec des constructions similaires mises au jour par exemple dans l'Eure sur les sites du Long Buisson à Évreux (Carpentier et al., 2004) et de La Bâte/Le Bochet à Thomer-la-Sogne (Lepert et Paez-Rezende, 2002, p. 98) ou à Richebourg dans les Yvelines 5 (Barat, 1999).

5. La fouille de la villa de Richebourg a mis en évidence trois petites chapelles alignées le long du chemin qui desservait l'établissement.
- Le foyer F 16. Cet aménagement extérieur à l'habitat a été creusé dans le substratum. De forme ovale, il est matérialisé par une auréole de rubéfaction dont le diamètre maximal atteint $1,50 \mathrm{~m}$ pour une profondeur conservée de $0,30 \mathrm{~m}$. La protection de cette structure n'est pas attestée, aucune trace de construction (poteaux) n'ayant été mise en évidence. Faute de liaison stratigraphique avec les faits archéologiques précédents et en l'absence d'éléments datants dans son comblement, la position chronologique du foyer dans le site reste hypothétique.

- Les dépotoirs. Une première unité (F 11) est excavée. D'une profondeur maximale de $0,33 \mathrm{~m}$, elle occupe une surface de $1,30 \mathrm{~m}^{2}$ et présente deux phases de comblement : la strate inférieure (US 11002) comprend des matériaux de démolition, essentiellement des éléments de toiture (tuiles et chaux); le niveau sus-jacent (US 11001) est constitué de rejets domestiques : céramiques, verre, restes fauniques, coquilles d'huîtres et éléments de parure en os.

Le stockage des déchets était également assuré par une zone de rejets (F 12) localisée dans l'angle nord-est de la cour. Faiblement excavée - sa profondeur ne dépasse pas $0,25 \mathrm{~m}$ - cette structure ne présente pas de limites bien marquées du fait de la dispersion du contenu. Son comblement associait des rejets culinaires, des céramiques (sigillées du Centre, céramiques communes, amphores), du mobilier métallique, quelques monnaies et des éléments de parure en os (épingles, cuillères à fard). La phase optimale d'utilisation de ce dépotoir se situe dans une fourchette début $\mathrm{II}^{\mathrm{e}} / \mathrm{milieu}$ III $^{\mathrm{e}}$ siècles (cf. infra, $\$$ chronologie).

\section{L'organisation de l'aire agricole}

L'étude de l'espace intérieur de la cour a révélé la présence d'installations agricoles mises en place sous le Haut-Empire, sans qu'il soit possible d'en déterminer la chronologie précise. Le plan restitué des installations est sans doute lacunaire, compte tenu d'une réoccupation partielle du lieu dans l'Antiquité tardive qui a probablement annihilé des structures préexistantes. Il met cependant en évidence une organisation raisonnée de la cour avec la présence d'un puits pourvu d'une aire de circulation périphérique réservée, aucun calage de poteau n'ayant été repéré dans un rayon d'une dizaine de mètres autour de celui-ci.

Des bâtiments en matériaux légers, à probable usage agricole, sont concentrés dans le secteur nord-est. Leur orientation respecte celle du mur d'enceinte. Ils sont matérialisés par des calages de pierres posées sur chant ou ayant basculé. D'éventuels poteaux non calés n'ont pu être repérés compte tenu du contexte géologique sableux peu propice à la conservation des négatifs. De dimensions variables, ces blocages souvent incomplets se présentent parfois sous la forme de véritables empierrements qui suggèrent des socles servant 


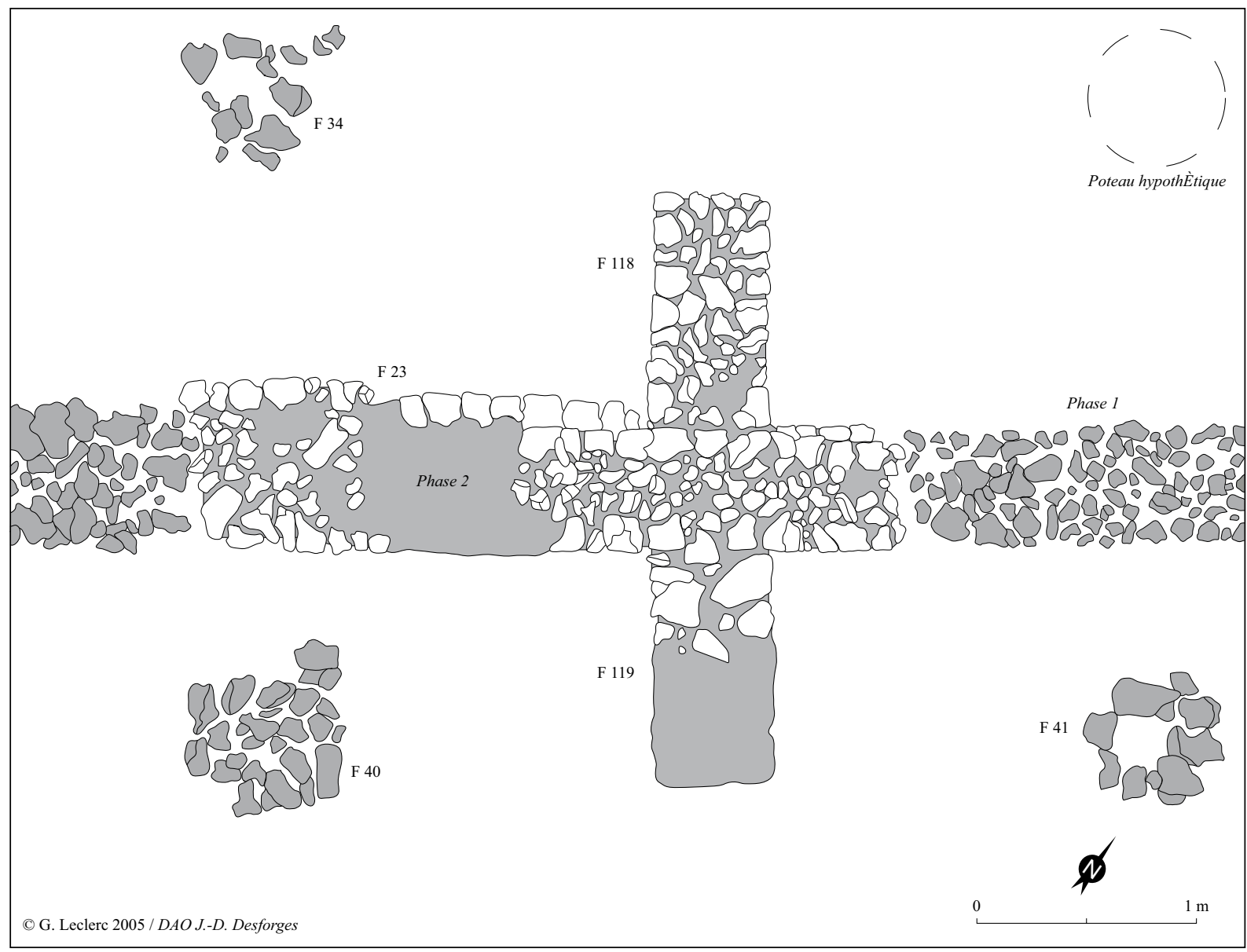

Figure 7 : Planimétrie du bâtiment 7 (porche).

Figure 7: Detailed plan of Building 7 (porch).

de support à des pieux de fort calibre pour compenser le manque de stabilité du substrat. Malgré la mise en évidence de 71 calages, la reconstitution du plan des bâtiments s'est avérée aléatoire du fait de l'absence de liaisons visibles au sol (sablières, cloisons...) entre les poteaux. Seuls certains groupes bien individualisés ont pu être interprétés.

- Le bâtiment 3. Cette construction sur poteaux a été implantée consécutivement à la condamnation du porche d'entrée de la cour et se présente sous la forme d'un rectangle très allongé de $16,36 \mathrm{~m}$ de longueur pour une largeur de $3,72 \mathrm{~m}$, soit une surface de $60 \mathrm{~m}^{2}$. Elle est matérialisée au sol par une rangée unique de sept poteaux alignés parallèlement au mur de façade de la cour. Les intervalles entre les calages varient de 2,10 m à 3,55 m. L'absence d'une seconde rangée de poteaux suggère que ce bâtiment était appuyé en appentis sur le mur, ses pignons étant confortés par deux poteaux placés contre le bord de la maçonnerie (F 109 et F 110). Le démontage d'un calage (F 51) a montré qu'il était réalisé en pierres calcaires associées à des fragments de tegulae. En coupe, le négatif du poteau présente un diamètre d'environ
$20 \mathrm{~cm}$ pour une profondeur conservée de $18 \mathrm{~cm}$. Son orientation au sud et sa morphologie apparentent cet appentis aux grandes constructions d'Athis-sous-Laon (Aisne) et de Guiry-Gadancourt (Val d'Oise), interprétées comme des étables (Pannetier 1996). Le décapage de l'espace intérieur du bâtiment n'a pas livré d'éléments susceptibles de conforter cette hypothèse.

- Les greniers. Trois autres ensembles cohérents de supports calés ont été individualisés.

- Le bâtiment 4 forme une première entité. De plan quadrangulaire, elle est représentée par quatre poteaux d'angles de fort calibre (F 19, F 37, F 47, F 58) auxquels un cinquième élément (F 18), placé à l'intérieur de l'aménagement, pourrait être associé. La surface de la structure a été évaluée à $14 \mathrm{~m}^{2}$ avec des distances entre poteaux d'angles de $3 \mathrm{~m}, 4 \mathrm{~m}, 3,70 \mathrm{~m}$ et $4,10 \mathrm{~m}$. Le démontage du calage $\mathrm{F} 19 \mathrm{a}$ permis d'évaluer le diamètre du pilier à $45 / 50 \mathrm{~cm}$. Le poteau a traversé la couche de terre végétale et entamé le substrat sableux induré dans sa partie supérieure. Cette construction peut être considérée comme un important grenier aérien. 
- Le bâtiment 5, presque carré, présente un plan et une morphologie comparables avec quatre piliers porteurs (F 39, F 46, F 56, F 57). Cette autre probable unité de stockage, d'une surface de $7,50 \mathrm{~m}^{2}$, est dotée d'une ossature moins puissante que la construction précédente, les poteaux n'étant que superficiellement enfoncés dans le sol. La seule relation existant entre ces deux greniers est leur orientation similaire et l'alignement de leur côté nord-ouest.

Le bâtiment 6 est une autre construction rectangulaire plus hypothétique, identifiée par trois calages seulement, le quatrième poteau n'ayant pas été mis au jour. D'une longueur de 3,20 m pour une largeur de $2,10 \mathrm{~m}$, cet aménagement est partiellement occulté par un niveau de sol postérieur constitué de matériaux récupérés.

D'autres nébuleuses de poteaux appartiennent à des constructions non identifiées dans le secteur très remanié au cours de la phase ultérieure.

- L'aire de battage. Outre les unités de stockage, la chaîne opératoire des activités agricoles comprend une plate-forme en argile fortement compactée et damée (F 73), qui a été interprétée comme une aire de battage des céréales (fig. 8). La structure, de forme rectangulaire, présente une épaisseur conservée de $0,30 \mathrm{~m}$ pour des dimensions de 2,20 $\mathrm{m}$ sur $1,90 \mathrm{~m}$. Elle semble avoir résisté aux labours bien que sa bordure ne soit plus visible. La présence de deux pierres encastrées sur chant dans l'argile suggère la présence d'un poteau axial (F 176), permettant d'effectuer le battage par

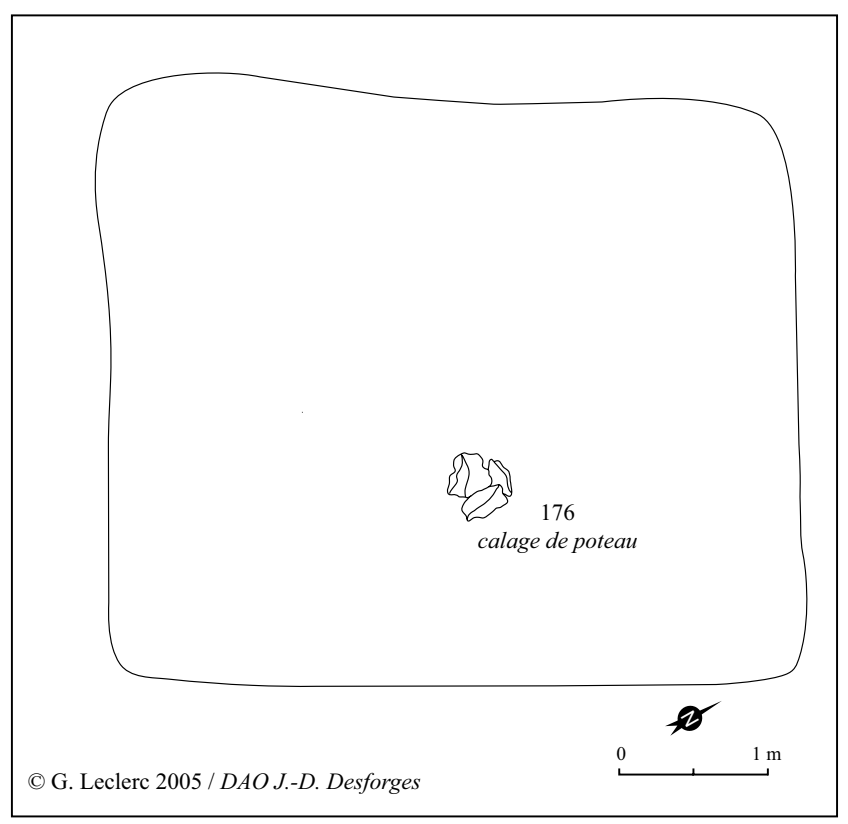

Figure 8 : Planimétrie de l'aire de battage F 73.

Figure 8: Detailed plan of Threshing area F 73. chauchage ${ }^{6}$. Des éléments de mobilier domestique ont été inclus dans l'argile : tuiles, tessons de céramiques, os d'animaux et coquilles d'huîtres.

- Une palissade? La limite entre les activités agricoles et l'espace résidentiel n'est pas clairement matérialisée et il ne semble pas qu'il ait existé une partie de la cour indépendante de l'habitat. Cependant un alignement de cinq calages (F 87, 88, 89, 98, 104), perpendiculaire au mur de cour nord-est, pourrait marquer l'emplacement d'une palissade isolant partiellement la zone réservée aux rejets domestiques (le dépotoir F 12).

\section{La fabrication de chaux}

Les investigations menées sur le site suggèrent que la chaux utilisée dans les constructions a pu être produite localement. Cette hypothèse s'appuie sur la découverte de plusieurs structures appartenant au processus de fabrication et de préparation de ce matériau. L'extraction de la matière première in situ est probable - même si elle n'a pas été mise en évidence - compte tenu de la présence de calcaire oolithique sur place. Les autres éléments d'une chaîne opératoire complète ont en revanche été identifiés : cuisson, extinction, malaxage et rebuts de fournées en remploi.

- Le four à chaux. L'ouverture d'une fenêtre de fouille au sud-ouest de la cour a révélé les vestiges ténus d'une probable chaufournerie situés près du bord extérieur du mur d'enceinte. La structure de cuisson n'est plus visible; elle a été totalement arasée comme cela est parfois le cas pour ce type d'aménagement ${ }^{7}$. Quelques témoins accréditent la présence de l'activité chaufournière : une fosse de travail (F 72), un muret en pierres sèches calcaires (F 161), une petite plateforme en tegulae (F 114) et des blocs incomplètement calcinés en remploi dans l'environnement immédiat (fig. 9).

La fosse F 72 était protégée par une toiture soutenue par un poteau central matérialisé par le calage F 108. Le comblement stratifié de la structure comprend un horizon supérieur (US 72001) formé des éléments effondrés du toit associés à des céramiques; la couche 72002 présente des fragments résiduels de chaux alors que les strates sous-jacentes (US 72003 et 72004) sont constituées respectivement de cendres et d'une concentration de gros blocs calcaires.

La fosse est limitée par un petit muret (F 161), dont un parement légèrement incurvé épouse vraisemblablement la forme de la chambre de cuisson et qui peut être interprété comme un seuil séparant le four de l'aire de travail (chargement, vidange). Une ouverture peu lisible dans le mur de cour et colmatée ultérieurement devait permettre une

6. Chauchage ou chaubage : système de battage consistant à frapper les gerbes contre un obstacle.

7. À Incarville (Eure), par exemple, l'épaisseur conservée de la sole ne dépasse pas 7 mm (Paez-Rezende 1997, p. 35-37). 


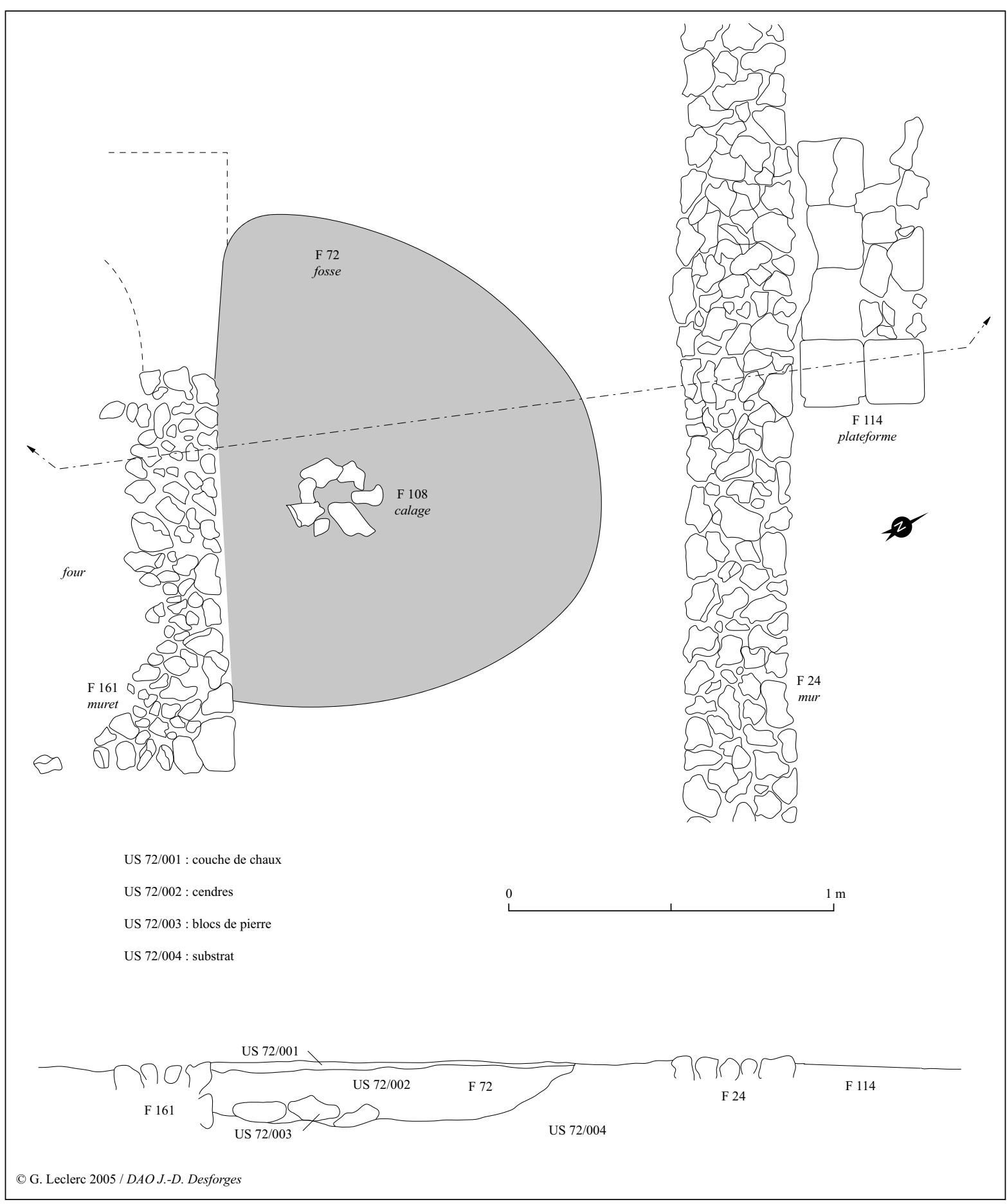

Figure 9 : Planimétrie et coupe stratigraphique du four à chaux.

Figure 9: Detailed plan and stratigraphic section of lime kiln.

relation entre l'unité de cuisson et une petite plate-forme en tegulae (F 114), destinée sans doute à l'extinction de la chaux par petites quantités. Une autre structure similaire (F 38), située à proximité, était sans doute elle aussi intégrée au processus de préparation de la chaux.
- Le bac à chaux. L'élément le mieux conservé de la chaîne de préparation est un bac excavé de forme parallélépipédique (F 13), creusé dans le substrat et situé seulement à $0,30 \mathrm{~m}$ du bâtiment résidentiel dont il adopte l'orientation (fig. 10). Soigneusement agencé à l'aide de tuiles à rebord, il 


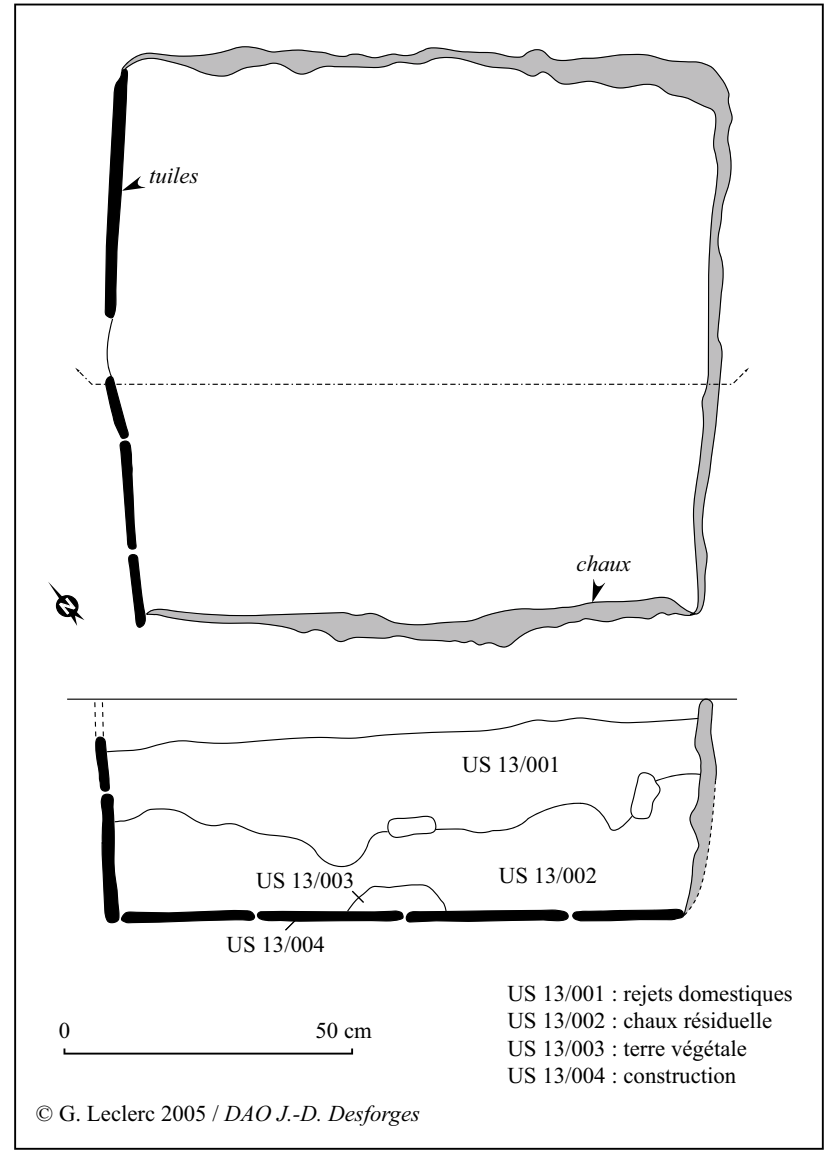

Figure 10 : Planimétrie et coupe stratigraphique du bac à chaux F 13.

Figure 10: Detailed plan and stratigraphic section of lime tank F 13.

occupe une surface de $2 \mathrm{~m}^{2}(1,45 \times 1,40 \mathrm{~m})$. Sa profondeur initiale est évaluée à $0,62 \mathrm{~m}$, ce qui correspond à deux rangs de tegulae superposées sur chant, le niveau supérieur ayant été écrêté par les labours. Le volume du bac est estimé à $1,24 \mathrm{~m}^{3}$. Les deux rangs de tuiles ne constituaient qu'une seule paroi du coffrage, les trois autres côtés étant réalisés en planches de bois dont la croûte de chaux résiduelle porte les empreintes. Le fond de l'excavation était également aménagé à l'aide de tegulae ${ }^{8}$ posées à plat sur un lit de chaux peu épais $(2 \mathrm{à} 3 \mathrm{~cm})$. Les restes du dernier malaxage sont encore en place et occupent la partie inférieure du remplissage (US 13002). L'épaisseur de cette couche varie de 10 à $33 \mathrm{~cm}$. Le bac, dans sa phase d'abandon, a servi de dépotoir (US 13001) associant des rejets culinaires, des fragments de céramiques et du mobilier de parure (fibule).

8. Ces tuiles à rebord ont pour dimensions L. $37,2 \mathrm{~cm}, 1.30 \mathrm{~cm}$, ép. 2,7 cm. D'autres modules de tegulae ont été utilisés sur le site : les tuiles intégrées dans les plateformes F 38, F 72 et F 114 (cf. infra) mesurent $32 \times 28 \mathrm{~cm}$ pour une épaisseur de $2,5 \mathrm{~cm}$.

\section{L'approvisionnement en eau}

- L'aqueduc. En 1997 et 1998, un aqueduc antique a été reconnu sur deux kilomètres depuis le captage des eaux au lieu-dit Escure jusqu'à l'entrée de la ville gallo-romaine de Sées (Leclerc 1997; 1998). Son statut (installation publique ou privée) n'a pu être précisé. Une dérivation longue d'une cinquantaine de mètres et matérialisée par un fossé inscrit dans le substrat sableux se dirige vers l'établissement du Grand-Herbage mais aucun vestige d'installation hydraulique n'a pu y être mis en évidence. Cependant, la découverte de trois frettes en fer dans des niveaux de matériaux remaniés suggère la présence de canalisation(s) en bois permettant la distribution d'eau.

- Le puits. L'alimentation en eau du site était également assurée par un puits (F 62) qui a été mis au jour dans la partie occidentale de la cour. Il a été fouillé manuellement jusqu'à 1,50 $\mathrm{m}$ de profondeur puis démonté à la pelle mécanique jusqu'au niveau actuel de la nappe phréatique, soit $-4,70 \mathrm{~m}$ par rapport au niveau de décapage. Il était pourvu d'une margelle en granite retrouvée en place, en porte-àfaux, à l'aplomb du conduit (fig. 11). Cette pierre, fissurée sur une ligne axiale, présente la forme d'un rectangle de $1,04 \mathrm{~m}$ sur $0,89 \mathrm{~m}$ pour une épaisseur de $18 \mathrm{~cm}$; elle est dotée d'un trou central circulaire légèrement ovalisé d'un diamètre moyen de $0,44 \mathrm{~m}$ et elle prend appui par ses qua-

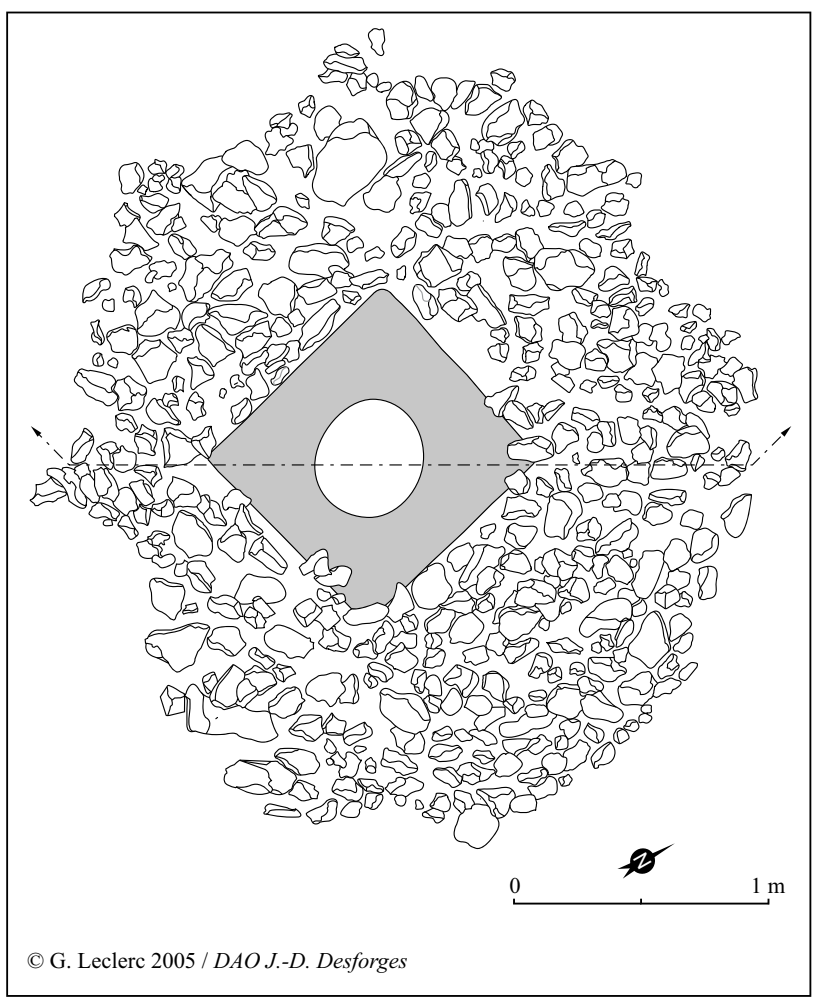

Figure 11 : Planimétrie de la margelle du puits F 62. Figure 11: Detailed plan of the edge of Well F 62. 
tre angles sur l'appareil cylindrique du conduit par rapport auquel elle est apparue sous-dimensionnée ${ }^{9}$. Pour pallier cet inconvénient, la partie supérieure du conduit a été maçonnée en encorbellement comme semble l'indiquer la dernière assise conservée.

Une coupe stratigraphique pratiquée dans l'axe médian du puits a montré que la chemise appareillée, d'une épaisseur maximale de $0,40 \mathrm{~m}$, était réalisée à l'aide de pierres calcaires grossièrement équarries et liées à l'argile. Ce dernier matériau était également utilisé sur une épaisseur de 0,30 m dans le doublage extérieur du conduit pour le consolider dans le terrain sableux. Les observations effectuées au cours du démontage de la structure ont montré que l'appareil n'existait que sur une hauteur d'environ deux mètres correspondant à l'épaisseur du niveau sableux. Le puits est ensuite constitué d'un simple trou percé sur 1,10 m à travers le calcaire sous-jacent qui surmonte deux niveaux d'argile dont la puissance n'est pas connue (fig. 12).

L'accès à la structure était protégé par une couronne de pierres calcaires partiellement dégradée au sud, du fait probablement de l'érosion agricole. Cet empierrement circulaire est conservé jusqu'à 3,20 $\mathrm{m}$ de rayon et son épaisseur varie de 10 à $15 \mathrm{~cm}$. Il était destiné à stabiliser le sol autour de la margelle et à permettre un certain confort d'accès.

Le comblement du puits, constitué de terre végétale, s'est avéré stérile si l'on excepte deux tessons de céramique commune sombre qui n'apportent pas d'indication chronologique précise. Cette carence en mobilier tient sans doute au fait que la fouille du conduit s'est arrêtée au niveau de la nappe phréatique, celle-ci empêchant l'accès au fond de l'aménagement.

\section{Chronologie des aménagements du Haut-Empire}

Faute de mobilier récupéré à l'intérieur de l'habitat, la datation de la phase initiale d'aménagement ne s'appuie que sur des données chronologiques issues du comblement du dépotoir domestique F 11, placé contre la paroi extérieure du mur sud-est et donc postérieur au bâtiment. Les marqueurs les plus précoces récupérés dans la structure associent deux tessons de sigillées du sud de la Gaule datables des années 50 à 70 de notre ère et un fragment de céramique plombifère de Vichy. Le premier état du Grand-Herbage n'est probablement pas antérieur au début de la période flavienne comme le suggère l'absence de productions des phases 1 et 2 de Lezoux.

Cette première implantation ne précède apparemment que de deux ou trois décennies la phase de réaménagement du

9. L'hypothèse d'une margelle en remploi ne peut être écartée.

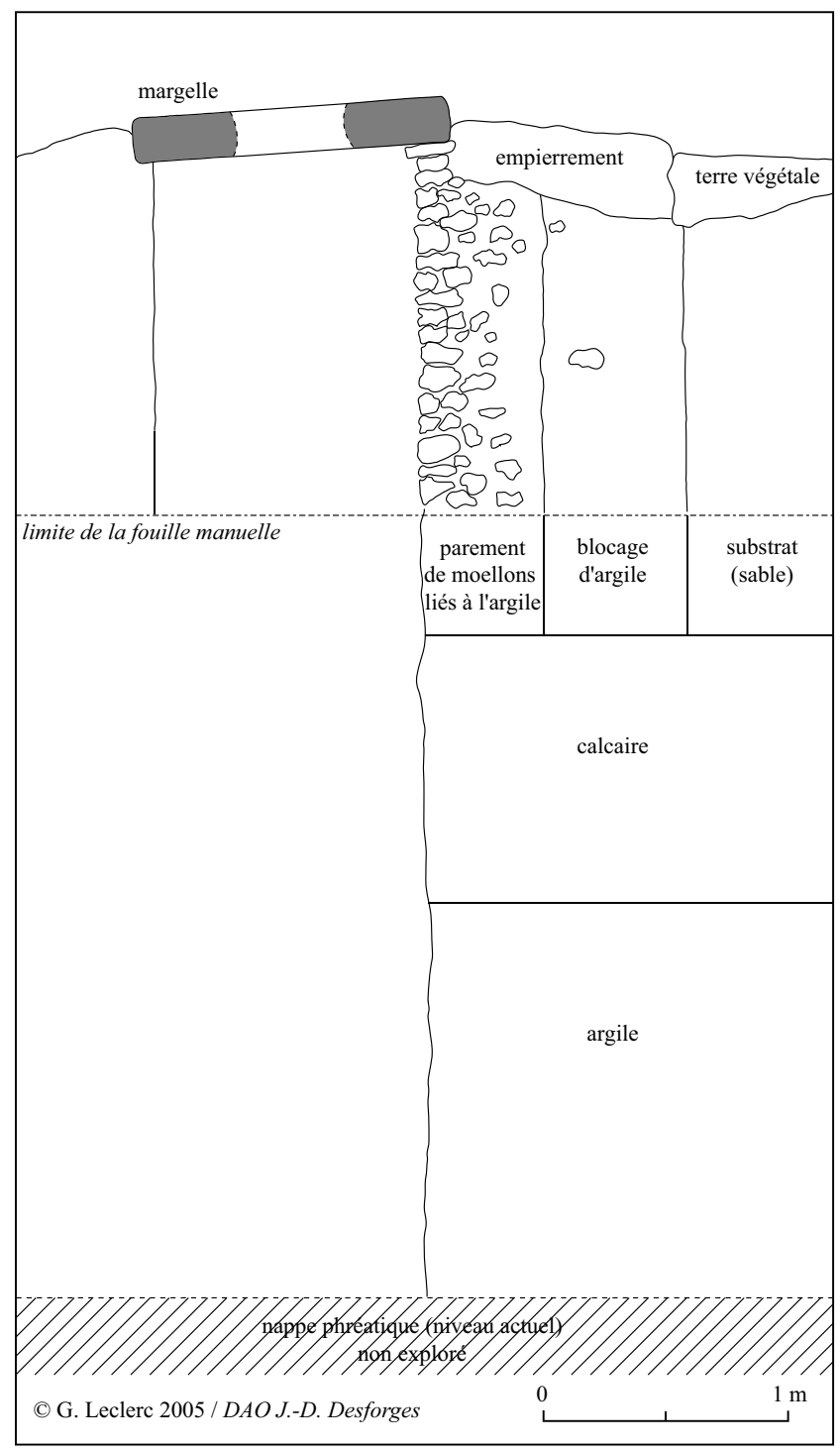

Figure 12 : Coupe du puits F 62. Figure 12: Section of Well F 62.

site, caractérisée par l'emploi de la chaux dans les constructions. Chronologiquement, l'indicateur le plus pertinent de cette restructuration est une fibule à arc triangulaire décoré de petites logettes émaillées ${ }^{10}$, datée de +70 à +100 . Elle a été retrouvée associée à des céramiques du dernier tiers du I ${ }^{\text {er }}$ siècle dans la couche d'abandon du bac à chaux F 13 (US 13001). La période de fonctionnement du site restructuré est clairement attestée aux $\mathrm{II}^{\mathrm{e}}$ et $\mathrm{III}^{\mathrm{e}}$ siècles apr. J.-C. au vu des mobiliers récupérés dans le dépotoir $\mathrm{F} 12$ et dans le comblement des structures excavées : sigillées des phases IV à VII de Lezoux, amphores Gauloise 12, cruches en céramique commune claire, productions de l'officine de $\mathrm{La}$

10. Type 26b1 de la typologie de Feugère (1985); cf. également Demarest ce vol. 
Bosse (Sarthe) ou d'ateliers associés, vase en verre Isings $85 \mathrm{~b}$, monnaies d'Antonin à Tetricus.

La chronologie des bâtiments sur poteaux est plus difficile à cerner compte tenu de la rareté du mobilier récupéré dans l'aire agricole. Elle ne repose que sur des marqueurs subjectifs tels par exemple des tessons de céramique présents dans l'espace intérieur ou dans l'environnement immédiat des structures; c'est le cas pour le bâtiment 3 avec deux tessons de céramique gris bleuté et un fragment de commune claire au bord du calage $\mathrm{F} 49$. L'espace intérieur du bâtiment $4 \mathrm{a}$ livré une anse d'amphore Gauloise 12 et cinq fragments de commune sombre à pâte grise. Un rebord de type La Bosse a été récupéré dans le calage $\mathrm{F} 56$ du bâtiment 5 . Enfin, à proximité immédiate du puits, ont été identifiés un fragment de sigillée Drag 37 de Lezoux, un rebord de Gauloise 12, 19 tessons de céramique commune claire dont un rebord de mortier, un col de cruche, et 31 éléments à couverte bleutée de type La Bosse.

\section{Les céramiques du Haut-Empire}

Cinq lots de céramiques ont été individualisés dans le comblement de structures excavées : dépotoirs $\mathrm{F} 11$ et $\mathrm{F} 12$, fourneaux $\mathrm{F} 9$ et $\mathrm{F} 10$ de l'hypocauste, bac à chaux F 13 (fig. 13 à 17 ; tabl. 1).

\section{Sigillées et amphores (fig. 13, 14)}

Les poteries sigillées issues des ateliers du sud de la Gaule sont pratiquement absentes du site hormis les deux exemplaires récupérés dans le comblement de la fosse F 11 (formes Hermet 28 et Ritterling 12).

Concernant les productions arvernes, l'essentiel de la documentation provient du dépotoir F 12 qui a livré du matériel inégalement fragmenté avec des formes Drag 31/ Lezoux 57, Lezoux 42, Drag 35/36, 37, 43 et 45, Curle 11, 15 et 23 ainsi que des fragments de Walters 79/80. Un fond de Drag 31 est estampillé ATILIANI $\mathrm{M}^{11}$. Le remplissage du premier praefurnium (F 9) de l'hypocauste comprend des formes Drag 37, Drag 33, Curle 11, 15 et 23, des Drag 31 et 42 ainsi qu'un rebord de Walt 79/80. Les sigillées du Centre récupérées dans les autres structures sont quantitativement faibles avec, dans le second praefurnium (F 10), un fond de Drag 18/31 estampillé REGALIS ${ }^{12}$ et, dans le bac à chaux F 13, deux tessons de Drag 35/36 et de Lezoux 42.

Côté amphores, la forme Gauloise 12 à pâte claire domine nettement les lots recueillis sans qu'il soit possible d'en déterminer la provenance, faute de connaître les ateliers de

11. Atilianus de Lezoux, actif fin $\mathrm{I}^{\mathrm{er}} /$ début $\mathrm{II}^{\mathrm{e}}$ siècles (Oswald, 1983, p. 26).

12. Période Domitien/Antonin, (Oswald 1983, p. 259)

\begin{tabular}{|l|c|c|c|c|}
\hline Structure F 9 & NT & \% NT & NMI & \% NMI \\
\hline Sigillées sud Gaule & $/$ & $/$ & $/$ & $/$ \\
\hline Sigillées Centre & 19 & 5,0 & 6 & 15,8 \\
\hline Amphores G 12 & 5 & 1,3 & 2 & 5,3 \\
\hline Amphores (autres) & $/$ & $/$ & $/$ & $/$ \\
\hline Mortiers & 2 & 0,5 & 1 & 2,6 \\
\hline Communes claires & 148 & 39,7 & 8 & 21,1 \\
\hline Communes sombres & 199 & 53,4 & 21 & 55,2 \\
\hline Total & $\mathbf{3 7 3}$ & $\mathbf{1 0 0} \%$ & $\mathbf{3 8}$ & $\mathbf{1 0 0} \%$ \\
\hline
\end{tabular}

\begin{tabular}{|l|c|c|c|c|}
\hline Structure F 10 & NT & \% NT & NMI & \%NMI \\
\hline Sigillées sud Gaule & $/$ & $/$ & & \\
\hline Sigillées centre & 1 & 0,4 & 1 & 4,8 \\
\hline Amphores G 12 & $/$ & & & \\
\hline Amphores (autres) & $/$ & $/$ & & \\
\hline Mortiers & $/$ & $/$ & & \\
\hline Communes claires & 47 & 20,9 & 8 & 38,1 \\
\hline Communes sombres & 177 & 78,7 & 12 & 57,1 \\
\hline Total & $\mathbf{2 2 5}$ & $\mathbf{1 0 0} \%$ & $\mathbf{2 1}$ & $\mathbf{1 0 0} \%$ \\
\hline
\end{tabular}

\begin{tabular}{|l|c|c|c|c|}
\hline Structure F 11 & NT & \% NT & NMI & \% NMI \\
\hline Sigillées sud Gaule & 3 & 0,4 & 2 & 4,3 \\
\hline Sigillées centre & 6 & 0,8 & 5 & 10,6 \\
\hline Amphores G 12 & $/$ & $/$ & $/$ & $/$ \\
\hline Amphores (autres) & 1 & 0,1 & 1 & 2,1 \\
\hline Mortiers & $/$ & $/$ & $/$ & $/$ \\
\hline Communes claires & 309 & 44,1 & 13 & 27,6 \\
\hline Communes sombres & 381 & 54,5 & 26 & 55,3 \\
\hline Total & $\mathbf{7 0 0}$ & $\mathbf{1 0 0} \%$ & $\mathbf{4 7}$ & $\mathbf{1 0 0} \%$ \\
\hline
\end{tabular}

\begin{tabular}{|l|c|c|c|c|}
\hline Structure F 12 & NT & \% NT & NMI & \% NMI \\
\hline Sigillées sud Gaule & $/$ & $/$ & $/$ & $/$ \\
\hline Sigillées centre & 69 & 2,5 & 17 & 7,8 \\
\hline Amphores G 12 & 29 & 1,0 & 10 & 4,6 \\
\hline Amphores (autres) & 9 & 0,3 & 2 & 0,9 \\
\hline Mortiers & 29 & 1,0 & 6 & 2,7 \\
\hline Communes claires & 1141 & 41,2 & 35 & 16,0 \\
\hline Communes sombres & 1495 & 53,9 & 149 & 68,0 \\
\hline Total & $\mathbf{2 7 7 2}$ & $\mathbf{1 0 0} \%$ & $\mathbf{2 1 9}$ & $\mathbf{1 0 0} \%$ \\
\hline
\end{tabular}

\begin{tabular}{|l|c|c|c|c|}
\hline Structure F 13 & NT & \% NT & NMI & \% NMI \\
\hline Sigillées sud Gaule & $/$ & $/$ & $/$ & $/$ \\
\hline Sigillées Centre & 2 & 1,0 & 2 & 10 \\
\hline Amphores G 12 & $/$ & $/$ & $/$ & $/$ \\
\hline Amphores (autres) & 1 & 0,5 & 1 & 5 \\
\hline Mortiers & 2 & 1,0 & 1 & 5 \\
\hline Communes claires & 48 & 25,1 & 4 & 20 \\
\hline Communes sombres & 138 & 72,3 & 12 & 60 \\
\hline Total & $\mathbf{1 9 1}$ & $\mathbf{1 0 0} \%$ & $\mathbf{2 0}$ & $\mathbf{1 0 0} \%$ \\
\hline
\end{tabular}

Tableau 1 : Décompte des types de céramiques pour les principales structures du Haut-Empire (NT : nombre de tessons; NMI : nombre minimum d'individus).

Table 1: Sumary of ceramic types for the main High-Empire structures (NT: number of shards; NMI: minimum number of individuals). 


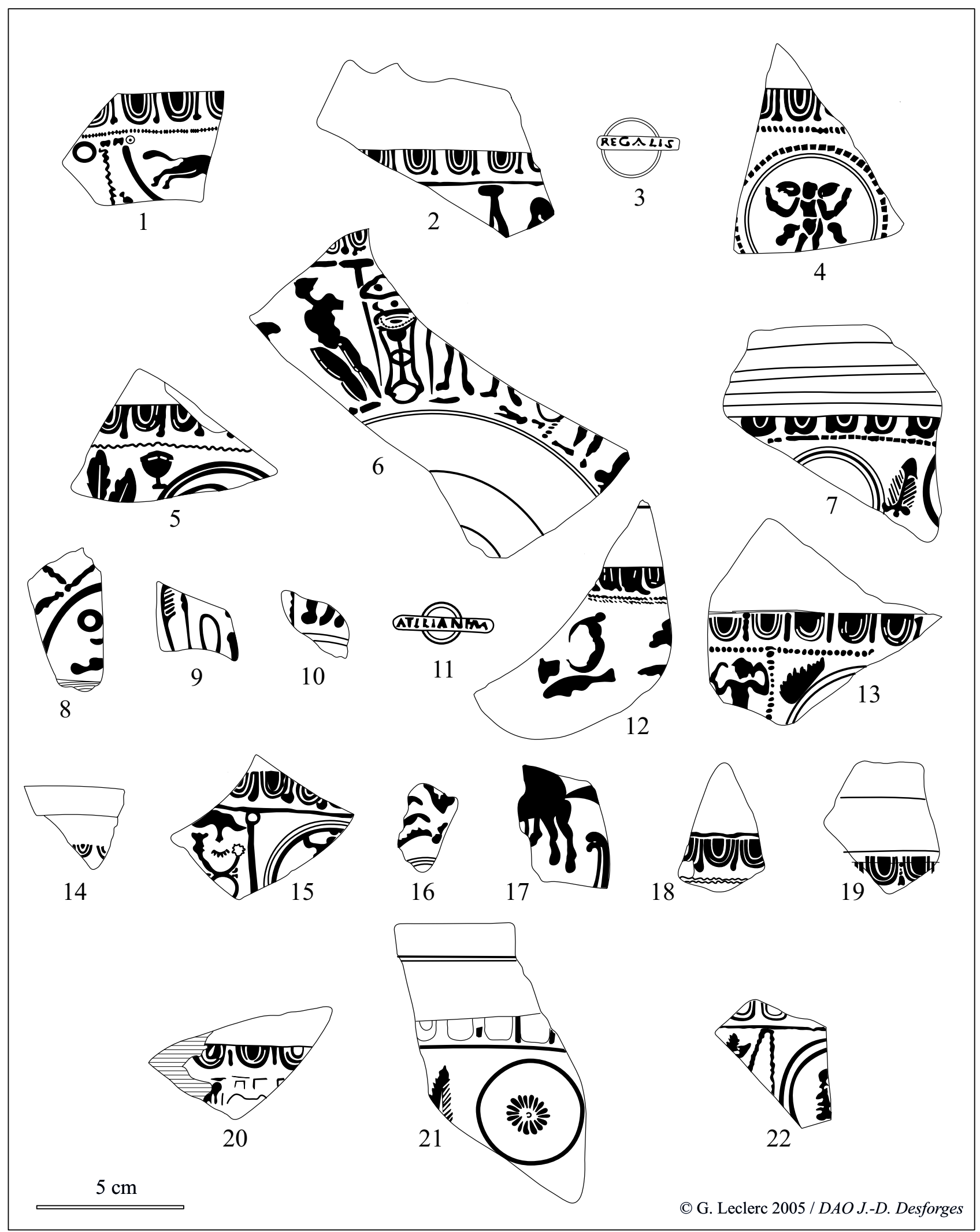

Figure 13 : Céramique sigillée : décors et estampilles. Praefurnium F 9 (1, 2); praefurnium F 10 (3); dépotoir F 11 (4, 5); dépotoir F 12 (6-22).

Figure 13: Terra sigillata ware: patterns and stamps.from praefurnia $F 9 \& F 10$, and from dumps F 11 \& 12 . 


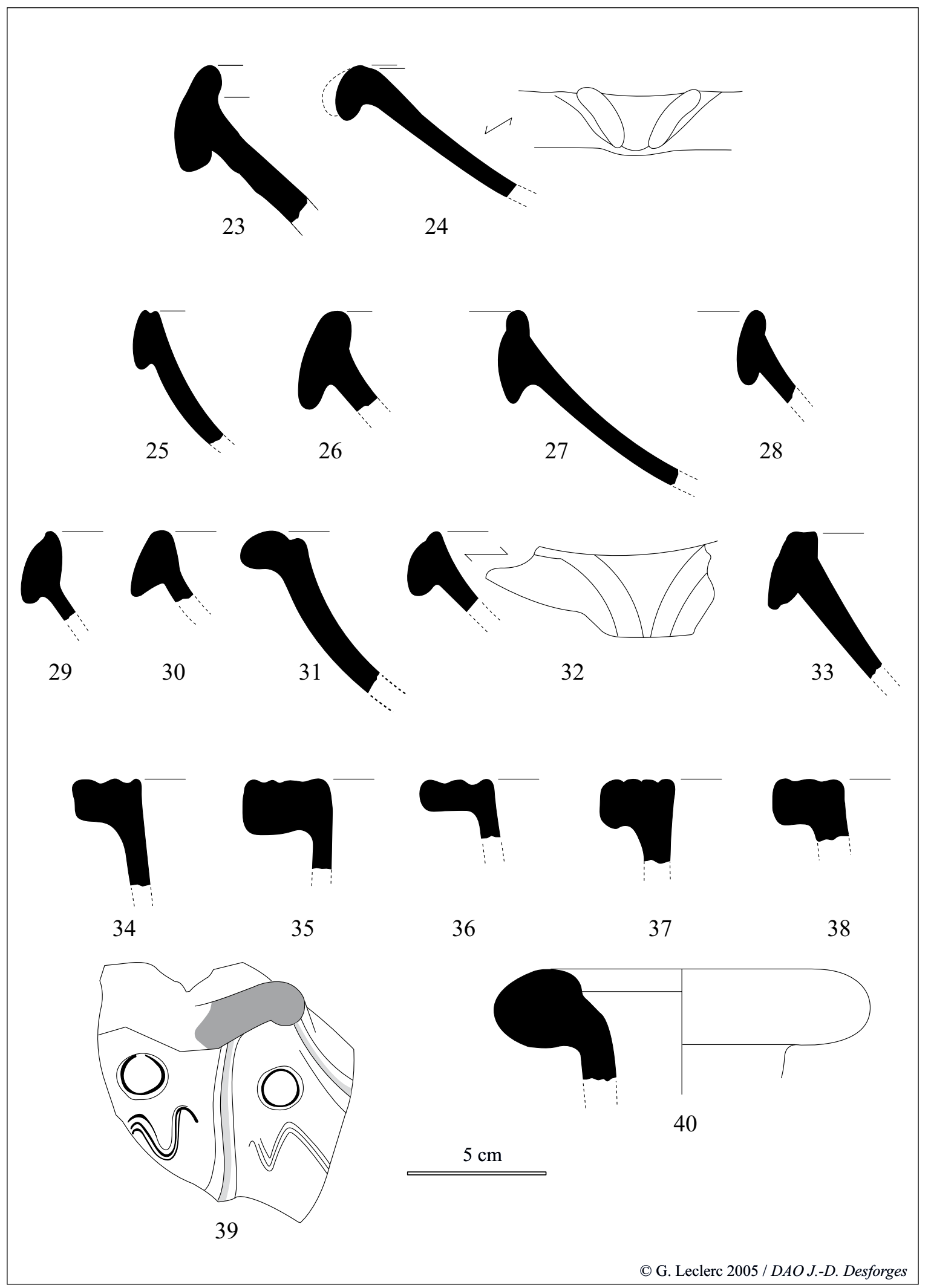

Figure 14 : Mortiers (23-33) et amphores (34-40). Praefurnium F $9(23,24)$; praefurnium F $10(25,26)$; dépotoir F 11 $(27,28)$; dépotoir F $12(29-40)$.

Figure 14: Mortars (23-33) and amphorae (34-40) from praefurnia F9\& F 10, and and from dumps F 11 \& 12. 
production. L'unique produit d'importation concerne les Dressel 20 avec quelques fragments de panses.

\section{Les céramiques communes (fig. 14-17)}

Les productions locales ou régionales, à cuisson oxydante, sont représentées par un premier groupe où prédominent nettement les mortiers à pâtes rouge-orangé ou beige et les cruches avec rebords en corniche et anses bifides.

Curieusement, les productions en pâte blanche de l'atelier local contemporain de la rue Saint-Pierre à Sées (Blaszkiewicz et Churin, 1991, p. 118-120) apparaissent absentes du site, excepté sept tessons dont l'origine n'est toutefois pas établie avec certitude.

Les produits à pâte sombre comprennent des formes basses dont des fragments de tripodes, une série de jattes et des assiettes à rebord rentrant. Le répertoire des formes hautes associe des vases de petit module, des pots à profil en $S$ inversé ou à bord éversé pourvu d'un méplat et d'autres à lèvres éversées triangulaires ou en crochet.

Les pâtes grises ou noires sont souvent calcaires ou micacées avec parfois des inclusions de quartz non calibrées. Un groupe de 13 tessons à paroi épaisse présente une pâte rougeâtre à surface noire, peut-être apparentée à la NPR du Bassin Parisien ou de l'Est.

La documentation comprend également des céramiques à surface bleutée, grésée ou non, et pourvue de bandes horizontales lustrées, Ces productions, originaires de l'officine de La Bosse (Sarthe) ou d'ateliers apparentés non connus, dominent nettement le lot récupéré dans le dépotoir F 12. Le catalogue des formes comprend des assiettes (classe 100), des bols tripodes avec ou sans collerette (classe 200), des jattes à rebord en bandeau (classes $606,607,608)^{13}$ et des pots à rebords moulurés. Les cruches sont nettement minoritaires (deux fragments d'anses). Ces mêmes formes sont omniprésentes sur le site et sont représentées, hors stratigraphie, dans un autre ensemble hétérogène de céramiques à pâtes grises et à surface lisse ou légèrement rugueuse.

Une autre production, très minoritaire, est caractérisée par des individus à pâte grise fine, légèrement quartzeuse et à surface gris cendré; quatre formes ont été identifiées : une cruche monoansée à embouchure simple éversée, deux pots à rebord éversé et une assiette.

Il faut signaler enfin quelques individus qui se différencient des lots précédents. Dans le bac à chaux F 13 par exemple, la couche de chaux résiduelle (US 13002), datée de la fin du $\mathrm{I}^{\text {er }}$ siècle, a livré un fragment de jatte à pâte sableuse gris foncé sans inclusions visibles et à surface grise lissée. Son profil présente une carène soulignée par deux gorges sur le bord vertical légèrement galbé et surmonté d'une lèvre débordante

13. D’après la typologie établie par G. Guillier (1997). à méplat horizontal; ce type s'apparente aux formes Ménez 103 de l'Ouest (ou 63b du Bourbonnais) et Santrot $150^{14}$. Un exemplaire de forme comparable a été répertorié dans l'Eure sur l'officine des Mares-Jumelles (Adrian et Lepert, 2000). Dans la même structure, l'US 13001 a livré un grand gobelet à col tronconique doté d'une lèvre droite amenuisée; la pâte en est grise, fine, sans inclusions visibles.

\section{L'abandon de l'établissement}

Dans la seconde moitié du III $^{\mathrm{e}}$ siècle, la fréquentation du site semble interrompue pour des raisons indéterminées, peut-être liées aux troubles de la décennie 275-286 qui ont entraîné nombre de destructions dans l'actuelle Normandie. Si action violente il y a eu, son impact n'est pas archéologiquement tangible : aucune couche d'incendie n'a été mise en évidence dans l'emprise de la partie résidentielle. La phase d'abandon de l'habitat se traduit concrètement par la destruction totale ou partielle des parties en élévation et le comblement des structures excavées, par exemple les deux praefurnia de l'hypocauste. Elle est datée par les éléments de mobilier les plus tardifs retrouvés dans les colmatages des structures comme quelques sigillées de la phase 7 de Lezoux (mortiers Drag 45) et des monnaies de Tetricus, omniprésentes dans le secteur résidentiel.

En ce qui concerne les dépendances à vocation agricole, ce processus de destruction n'apparaît pas aussi clairement. Seule, l'absence de mobilier domestique de la seconde moitié du III ${ }^{\mathrm{e}}$ siècle dans l'emprise des bâtiments de la cour suggère la disparition concomitante des structures en matériaux périssables.

\section{LA RÉOCCUPATION DU IV ${ }^{\mathrm{E}}$ SIÈCLE}

\section{La nouvelle topographie de l'établissement}

La phase d'abandon de la seconde moitié du III siècle précède une réorganisation majeure du site sans qu'un hiatus de l'occupation puisse être archéologiquement attesté. Il a simplement été constaté l'absence de monnaies pour la période 273-286 (de Tetricus à Maximien) ${ }^{15}$.

La nouvelle organisation du domaine est caractérisée par un déplacement de l'aire domestique et des activités agricoles vers l'est et le nord (fig. 18). L'identification des nouvelles installations repose sur la présence de matériaux (tuiles, éléments d'hypocauste, pierres) systématiquement récupérés sur

14. D'après les typologies d'Y. Menez $(1985,1989)$ et de M-H. et J. Santrot (1979).

15. Cet argument $a$ silentio n'est pas déterminant, la période 274-294 étant caractérisée par une faible circulation monétaire. 


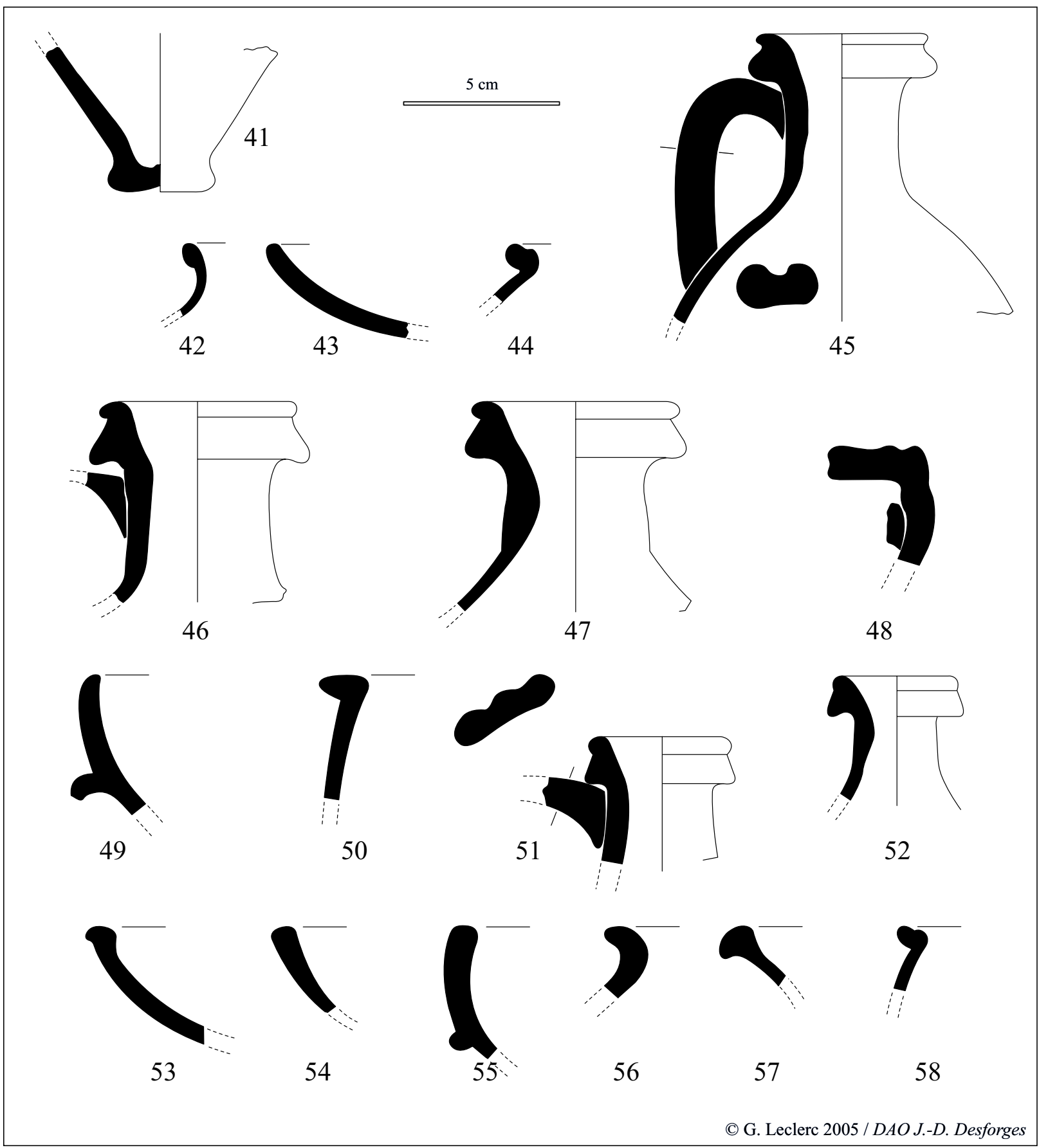

Figure 15 : Céramiques communes claires. Praefurnium F9 (41-44); dépotoir F 11 (45,46); dépotoir F 12 (47-58). Figure 15: Light common wares from Praefurnium $F 9$ and from dumps $F 11 \& F 12$..

l'habitat du Haut-Empire et remployés, soit en sols de circulation soit en aires de stabulation à l'intérieur de nouveaux bâtiments. Cette option révèle l'adaptation des nouveaux occupants au problème récurrent de l'instabilité du substrat sableux. Cet apport de matériaux, réutilisés également dans la construction de quelques structures (bacs, éléments d'habitat) constitue un fossile directeur privilégié pour l'iden- tification des aménagements de l'Antiquité tardive. Il est conforté par des éléments de datation, essentiellement des monnaies du IV ${ }^{\mathrm{e}}$ siècle et des céramiques d'Argonne.

Fin $\mathrm{III}^{\mathrm{e}} / \mathrm{début} \mathrm{IV}^{\mathrm{e}}$ siècles, la nouvelle topographie de l'établissement se caractérise par la création d'une nouvelle aire d'habitat et une réorganisation de l'espace agricole s'appuyant sur une extension de la cour, désormais reconnue 


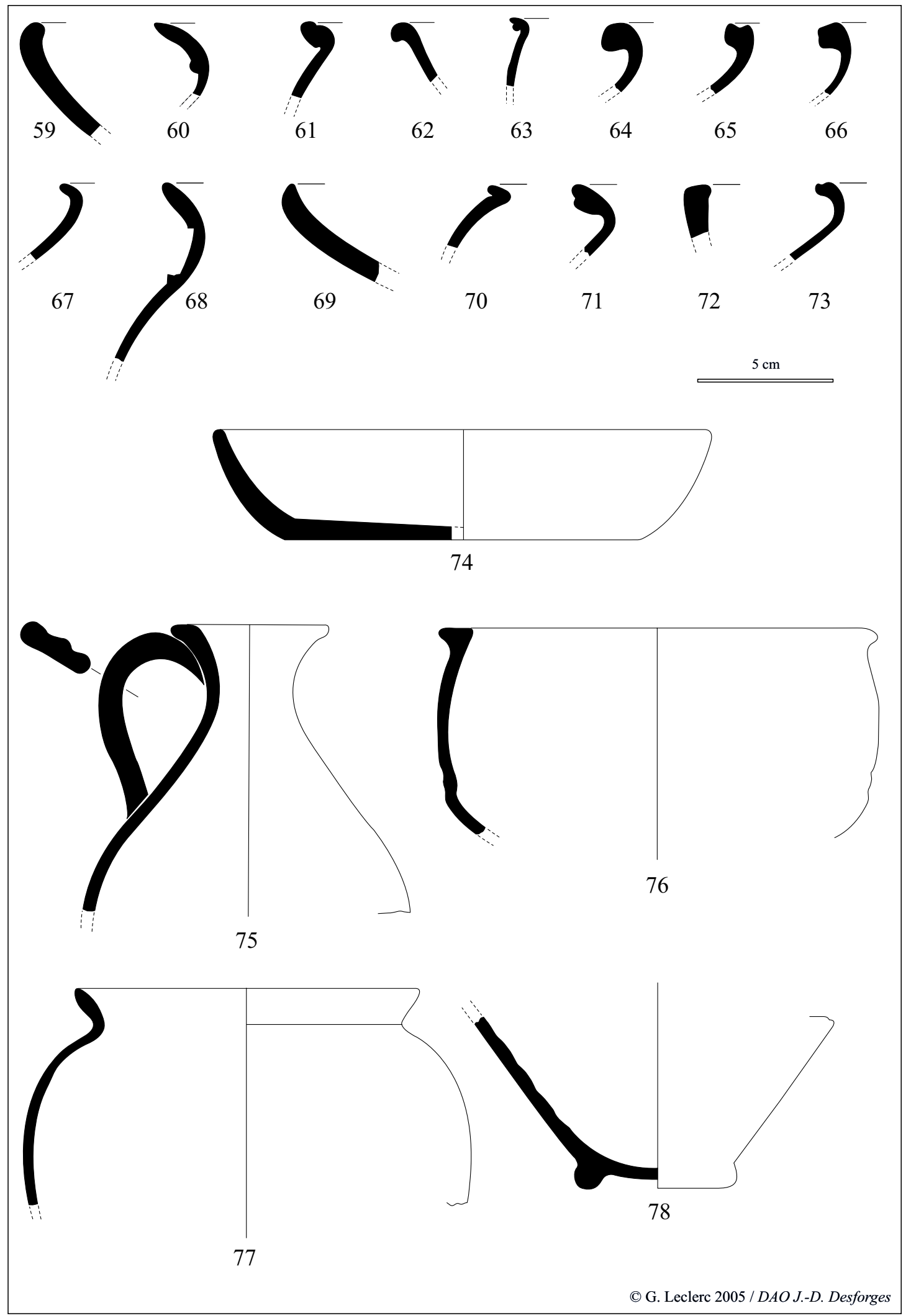

Figure 16 : Céramiques communes sombres. Praefurnia F 9 et F 10 (59-67); dépotoir F 11 (68-75); bac à chaux F 13 (76-78).

Figure 16: Dark common wares from praefurnia $F 9$ \& $F 10$, dump $F 11$ and from lime tank $F 13$. 


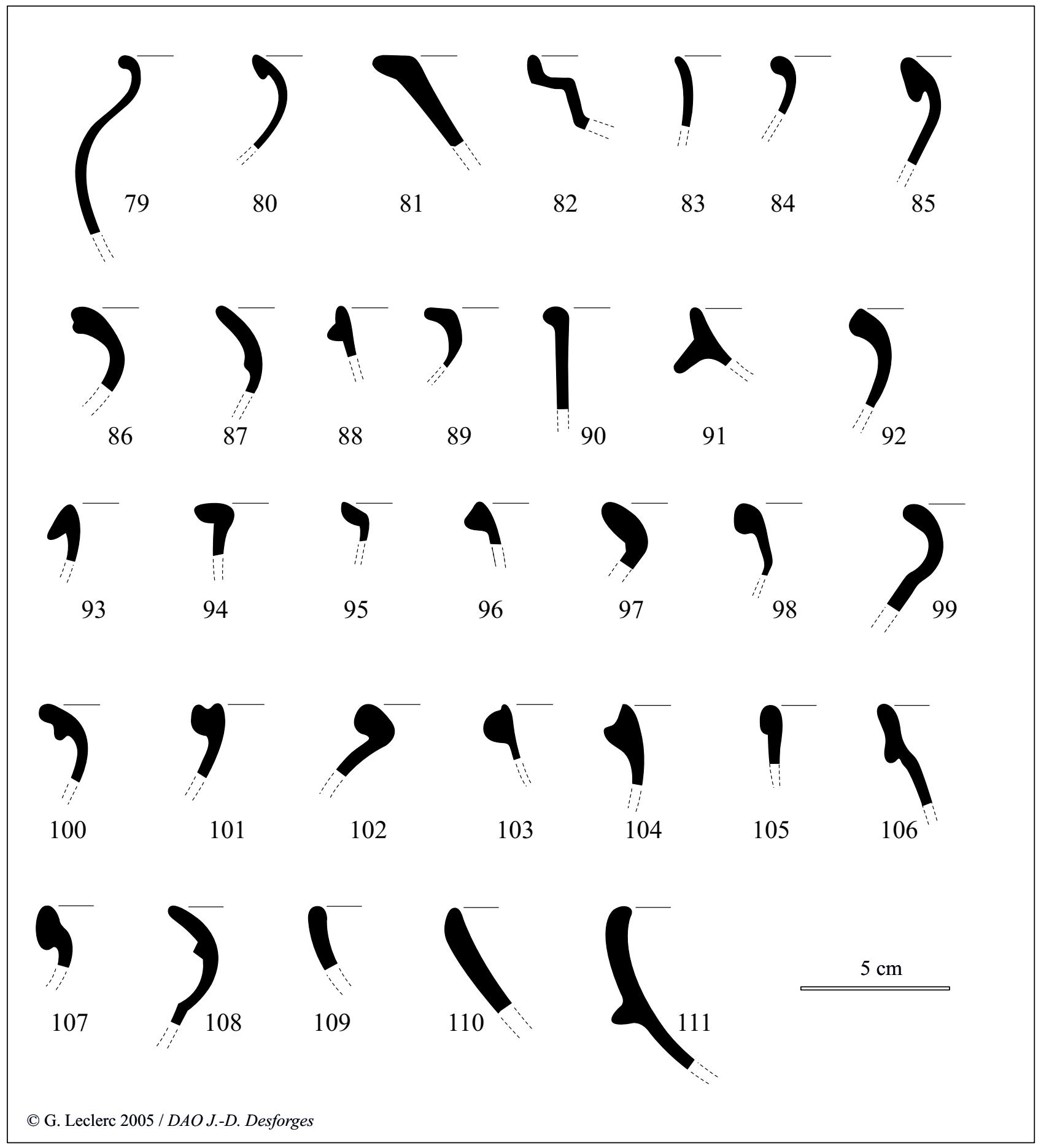

Figure 17 : Céramiques communes sombres. Dépotoir F 12 (79-111).

Figure 17: Dark common wares from dump F 12.

sur une surface de $1250 \mathrm{~m}^{2}$. La nouvelle pars agraria est partiellement limitée par un mur d'enceinte dont l'orientation reprend celle de la cour initiale mais dont les fondations présentent des caractéristiques architecturales différentes de celles de la phase précédente. Elles sont élaborées en pierres calcaires brutes de dimensions hétérogènes, associées à des tuiles en remploi. Au nord-est, un tronçon, long de 65,5 m et parallèle au mur latéral de la cour 1, s'appuie en retour sur les restes de l'habitat du Haut-Empire. Il est visible par sa fondation, d'une largeur moyenne de $0,70 \mathrm{~m}$ pour une 
hauteur variant de 0,45 à $0,55 \mathrm{~m}$. Près de son angle est, ce mur présente une première interruption de $8,50 \mathrm{~m}$ qui correspond à un passage, doté sans doute d'un système de fermeture (palissade amovible?) attesté par la présence de deux calages de poteaux (F 99 et F 103). Une seconde ouverture devait permettre une communication avec une petite construction extérieure sur solin de pierres (bâtiment 10). Au sud-est, l'enceinte, prolongée à angle droit et sur une longueur de $15 \mathrm{~m}$, est connectée à l'habitat ruiné. Au nordouest, la cour est limitée par un mur dégagé sur une longueur de $61 \mathrm{~m}$ et dont la hauteur conservée, évaluée en deux endroits, s'amenuise vers l'ouest jusqu'à l'arasement complet. Il présente une interruption large de 3,50 $\mathrm{m}$ sans aménagement visible. Une série de calages adossés à ce tronçon de mur suggère l'utilisation d'un échafaudage. La nouvelle aire agricole n'est pas fermée au sud-ouest, soit que sa limite ait disparu du fait de l'érosion agricole, soit qu'elle n'ait occupé qu'un espace semi-ouvert.

Le fonctionnement du domaine ainsi remanié parât organisé autour du " couloir " délimité par les murs latéraux parallèles des deux cours au nord-est. Situé en bordure de la nouvelle aire d'habitat, ce passage, au sol consolidé par un apport de matériaux, mettait en relation la seconde cour et le secteur méridional du domaine. La prise en compte des restes des bâtiments résidentiels du Haut-Empire dans la nouvelle organisation suppose le maintien d'une activité, non attestée archéologiquement, à l'intérieur des structures ruinées

\section{Une nouvelle aire d'habitat}

La nouvelle aire domestique est implantée vers le nord-est, à l'extérieur de la cour et à environ $40 \mathrm{~m}$ de l'entité résidentielle initiale. La morphologie de la nouvelle occupation n'a pu être intégralement reconnue car la fouille est restée limitée dans ce secteur. Seule a été identifiée une concentration d'éléments d'habitat non liés stratigraphiquement entre eux : des calages de poteaux, un lambeau de sol, deux foyers à usage domestique et quelques structures associées (fig. 19).

Les emplacements de quelques poteaux de bois intégrés à une ou plusieurs constructions ont été localisés par leurs calages de pierres; ceux-ci n'ont livré aucun marqueur chronologique mais ont réutilisé des matériaux provenant du bâtiment ruiné (cf. supra). Le démontage du poteau F 144 a montré que son diamètre avoisinait $0,50 \mathrm{~m}$ et que sa partie enterrée n'excédait pas $0,45 \mathrm{~m}$ (fig. 20). Trois calages sont apparus très groupés, ce qui pose le problème de leur contemporanéité : on ne peut écarter la possibilité d'un réaménagement ou de réparations laissant subsister les blocages successifs. L'absence de structures excavées suggère l'existence d'un habitat appartenant vraisemblablement au type " construction de bois au niveau du sol ${ }^{16}$ " (Van Ossel 1992).

Plusieurs autres éléments constitutifs d'un espace domestique sont à noter (cf. fig. 19).

- Un lambeau de sol (F 172) constitué d'une couche de limon argileux compacté, épaisse de $3 \mathrm{~cm}$ et posée directement sur le substrat sous-jacent, sans radier. Plusieurs monnaies du IV ${ }^{\mathrm{e}}$ siècle et des tessons d'Argonne ont été récupérés à sa surface.

- Associée certainement à l'habitat, une sole de foyer quadrangulaire indurée et de couleur brun sombre (F 164) a été élaborée en argile limoneuse. Cette aire de combustion, de type ouvert ${ }^{17}$, présente sur son pourtour des lambeaux de calage (fragments de briques et de pierres). Elle occupe une surface de $2,5 \mathrm{~m}^{2}$ pour une épaisseur maximale de $4 \mathrm{~cm}$. Une couche cendreuse et des rebuts de cuisine (ossements d'animaux) occupent son environnement immédiat et attestent l'usage domestique de ce foyer, apparemment placé à l'extérieur de l'habitation.

- À trois mètres au nord de F 164, une tache circulaire rougeâtre d'environ un mètre de diamètre témoigne d'une autre activité liée au feu et sans doute intégrée également à l'entité domestique. Le démontage partiel de la structure a montré qu'il n'y avait pas de foyer aménagé (absence de sole) mais que l'activité de cuisson avait été pratiquée directement sur le sol naturel.

- En limite sud de l'espace étudié, a été mise au jour une plate-forme carrée d'un mètre de côté. Cette structure F 147, dont la fonction n'a pu être précisée, est constituée d'une seule couche de moellons calcaires calibrés, posée directement sur le substrat. La réutilisation de pierres brûlées provenant sans doute du four à chaux est visible dans une rangée de pierres placée en bordure de la structure. Chronologiquement, cette construction est postérieure au mur de cour 2, dans lequel elle est légèrement encastrée.

- Deux autres aménagements aux fonctions non déterminées complètent l'organisation du secteur domestique : d'une part, une petite fosse F 167 comblée avec des ossements d'animaux soigneusement empilés, d'un poids de $2,5 \mathrm{~kg}$ et d'autre part une concentration (F 145) de matériaux de récupération, posée directement sur le sol naturel et qui comprend des restes d'hypocauste (pilettes, suspensurae), quelques pierres et des éléments de toiture (chaux, tegulae, imbrices).

16. P. Van Ossel distingue trois types d'habitats en bois pour le BasEmpire : les constructions au niveau du sol, les cabanes excavées et les constructions de type mixte.

17. Ce type d'aménagement est connu au Bas-Empire (cf. Van Ossel, 1992). 


\section{Réutilisation partielle de la cour du Haut-Empire}

Au IV siècle, une partie des activités agricoles reste concentrée dans la première cour dont le mur périphérique initial - conservé ou partiellement détruit - sert d'appui à deux petites constructions en matériaux périssables (bâtiments 8 et 9), identifiables par quelques trous de poteaux et un sol en matériaux remployés.

La réutilisation de la cour initiale s'avère plus difficile à caractériser; il paraît néanmoins acquis que cet espace a été partiellement réoccupé. Ce constat s'appuie en premier lieu sur quelques éléments révélés par la fouille, plusieurs calages ayant livré soit des matériaux en remploi soit des marqueurs chronologiques comme par exemple un tesson de sigillée d'Argonne décoré à la molette, associé à une monnaie de Gratien. En outre, la zone réoccupée apparaît légèrement surélevée par rapport au reste de la cour du fait d'une sédimentation anthropique plus importante ( 30 à $40 \mathrm{~cm}$ de terre végétale au lieu de 25 à $30 \mathrm{~cm}$ ). Enfin, le décapage manuel de ce secteur a livré un ensemble de témoins du IV $^{e}$ siècle tels que des poteries d'Argonne, deux tessons de céramique métallescente tardive et des monnaies de la dynastie constantinienne.

La restitution du plan des constructions sur poteaux apparaît plus hypothétique faute d'éléments discriminants susceptibles d'isoler les calages de la phase précédente. Il semble qu'au moins un aménagement de forme subcirculaire (enclos palissadé?) était implanté dans l'espace réoccupé. Un bac hexagonal (F 92), construit en tegulae assemblées à la chaux, semble associé à cette construction et peut être interprété comme une mangeoire ${ }^{18}$. À proximité, une plate-forme en pierres brûlées (F 106), élaborée avec des rejets du four à chaux, était sans doute intégrée à ce dispositif. Il paraît probable que le puits perdure dans la nouvelle organisation comme le suggèrent trois tessons de céramique d'Argonne, de formes Chenet 320 et 324, récupérés dans la couronne de pierres périphérique. L'aqueduc, par contre, a sans doute été abandonné ${ }^{19}$.

Pareillement, l'utilisation de chaux dans certaines structures accrédite la pérennité de l'activité de chaufournerie. Plusieurs indices chronologiques confortent cette hypothèse, en particulier un fond d'Argonne Chenet 320 et une monnaie de Valentinien ${ }^{\text {er }}$ récupérés dans la couche supérieure (US 72001) du comblement de la fosse de travail (F 72) associée au four à chaux.

18. La présence de mangeoires sur les sites ruraux antiques a été mise en évidence sur le site de Pluméliau (Morbihan), mais sous forme d'aménagements en bois (Courbot 1998).

19. Trois frettes de canalisation en fer ont été récupérées dans les matériaux du Haut-Empire en remploi.

\section{Les installations de la nouvelle cour}

Dans l'extension de la cour initiale, l'interprétation des données concernant des activités agricoles se heurte au manque de lisibilité du plan d'ensemble (fig. 18). Aucune restitution de bâtiment n’a été possible à partir des 19 calages dispersés dans l'espace concerné. Aucun grenier n’a ainsi été mis en évidence; par contre, diverses structures méritent description.

- Les aménagements en tegulae. Deux bacs comparables à la structure F 92 de la première cour participaient sans doute aux activités d'élevage du secteur (nourriture du bétail ou abreuvoir?). Ces entités, F 127 et F 141, sont construites en tuiles liées à la chaux, posées à plat pour le fond et sur chant pour le pourtour. F 127, de forme hexagonale, est arasée et ne conserve plus que le fond et la partie inférieure du bord (fig. 21); F 141, à l'état d'arasement plus prononcé, ne subsiste plus que par un lambeau du fond et du rebord. La position de ces deux structures ne permet pas de les intégrer dans une organisation cohérente. Si le premier bac est proche de plusieurs calages (F 128, F 129, F 133, F 151 et F 163), le second, par contre, apparait isolé. Un autre aménagement (F 138), en tuiles et matériaux en remploi (briques à encoche provenant d'un foyer de l'hypocauste), se présente sous l'aspect d'une petite plate-forme rectangulaire d'architecture comparable à deux structures mises au jour dans la première cour ( $\mathrm{F} 38$ et $\mathrm{F}$ 114) et dont la fonction est sans doute liée à la chaufournerie.

- La fosse F 130. Dans l'angle sud-ouest de la cour 2, une petite fosse circulaire (F 130) témoigne d'une possible extraction de sable. Cette entité présente un diamètre de $1,70 \mathrm{~m}$ pour une profondeur maximale de $0,50 \mathrm{~m}$. Son comblement homogène associe des pierres brutes, quelques fragments de tuiles à rebord et des céramiques communes à pâte grise.

- Le bâtiment 10. Un radier de pierres sèches très dégradé marque l'emplacement d'un petit bâtiment de surface modeste estimée à $12 \mathrm{~m}^{2}$ et situé à proximité du nouvel habitat. Il a été localisé contre le bord extérieur du mur latéral nord-est de la seconde cour avec laquelle il communiquait.

\section{Chronologie des structures de l'Antiquité tardive}

L'attribution chronologique de ces nouvelles structures à l'Antiquité tardive s'appuie sur une convergence des marqueurs associant 23 monnaies du Iv siècle - dont la majorité appartient à la période 324-361 (Constantin et dynastie), une remarquable fibule « en arbalète à ressort » d'origine germanique (type Keller 6), datable de 275 à $375^{20}$ (Philippe, 1999, p. 194-195; Demarest, ce vol.), et un lot de cérami-

20. Il s'agirait de l'un des modèles originaires de la Basse-Saxe. Les apports constitués par l'implantation de populations germaniques en Gaule du Nord s'étendent à l'ouest de la Seine jusqu'en Normandie et en Pays de Loire. 


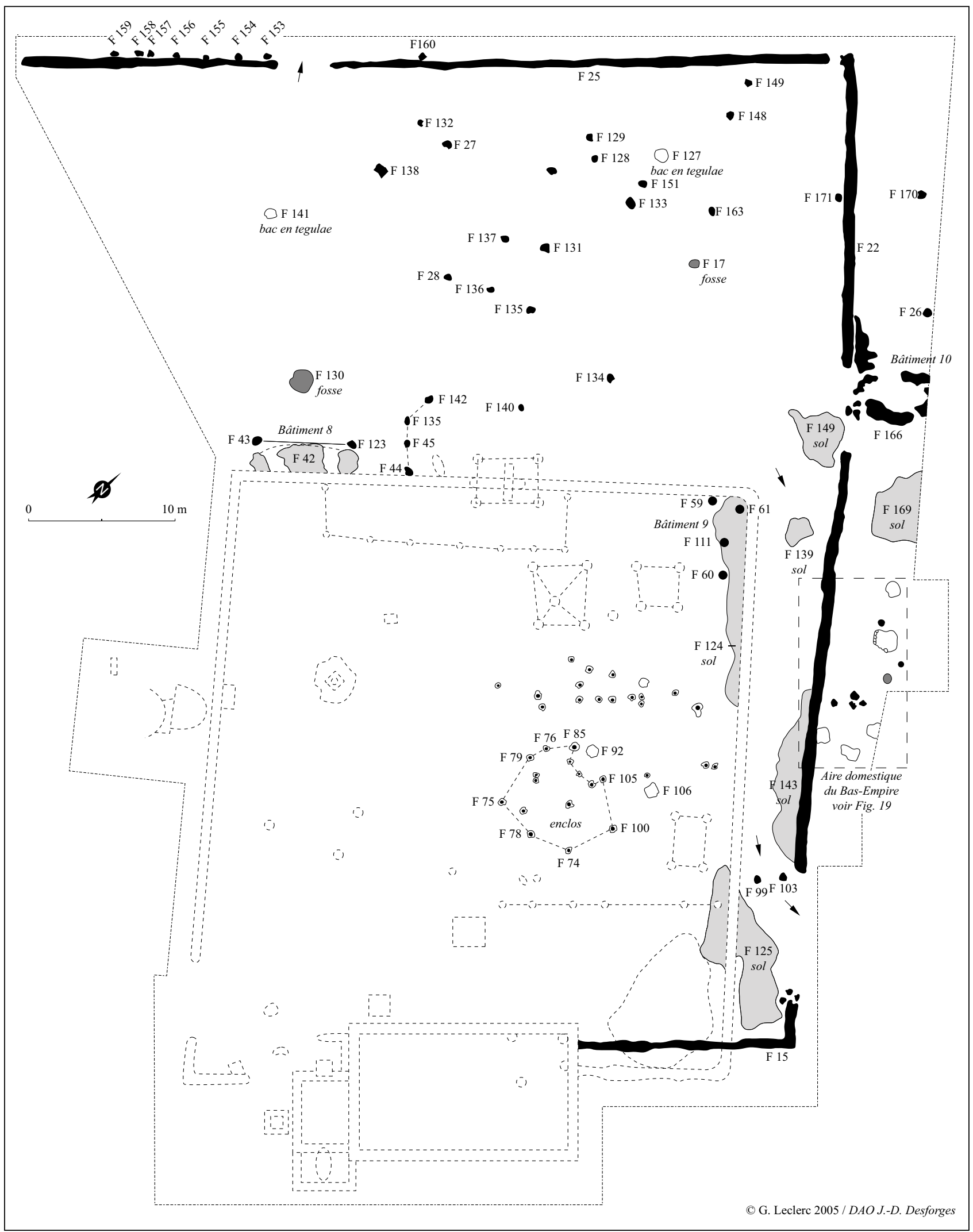

Figure 18 : Sées, Le Grand-Herbage : aménagements du Bas-Empire.

Figure 18: Low-Empire layout. 


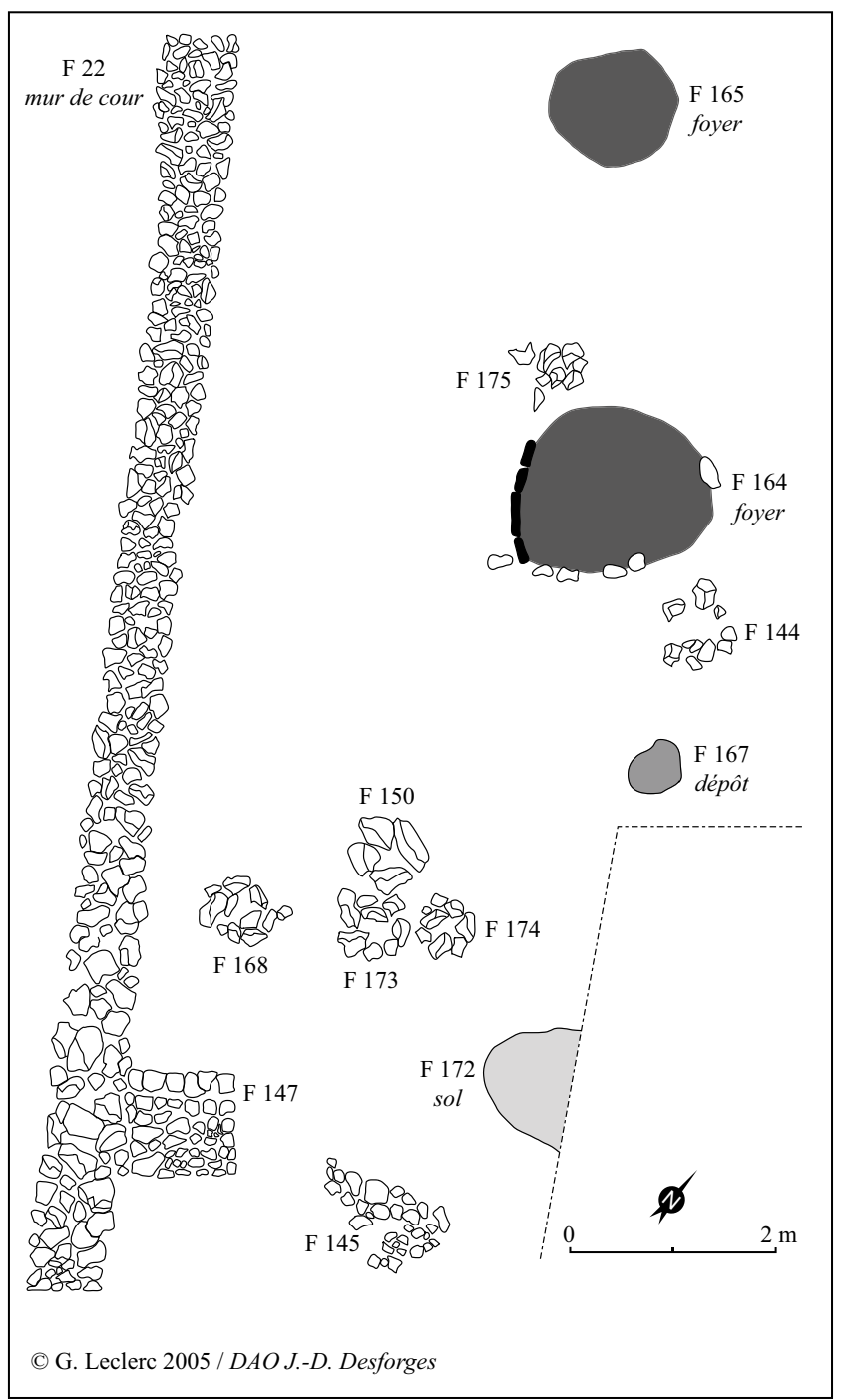

Figure 19 : Planimétrie de l'aire domestique du Bas-Empire. Figure 19: Detailed plan of the Low-Empire domestic area.

ques d'Argonne dont certaines présentent des molettes des groupes 2 et 5 de Hübener respectivement attribuées aux séquences 330-365 et 360-39 d'après la chronologie proposée par M. Feller (Feller, 1991, p. 163).

Le comblement de la fosse F 130 a livré des artefacts chronologiquement contemporains de l'habitat, avec en particulier une monnaie de Licinius.

\section{Les céramiques de l'Antiquité tardive}

La documentation céramique est issue, d'une part du décapage des structures d'habitat, d'autre part de la zone réoccupée de la cour 1 . Du mobilier du Iv siècle a également été récupéré dans la fosse F : 130, essentiellement de la céramique commune sombre (tableau 2; fig. 22-23).

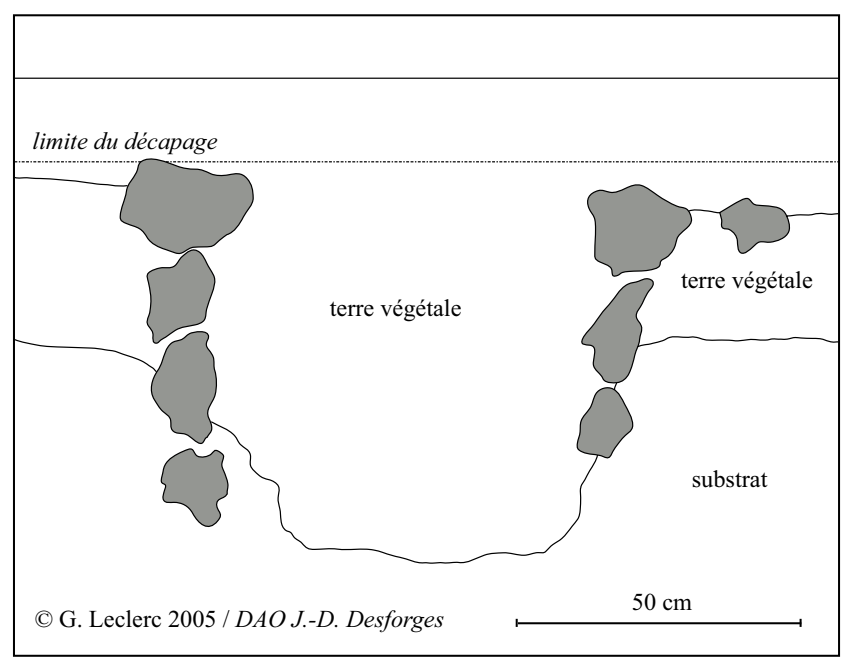

Figure 20 : Coupe du calage du poteau F 144. Figure 20: Section of Post F 144 packing.

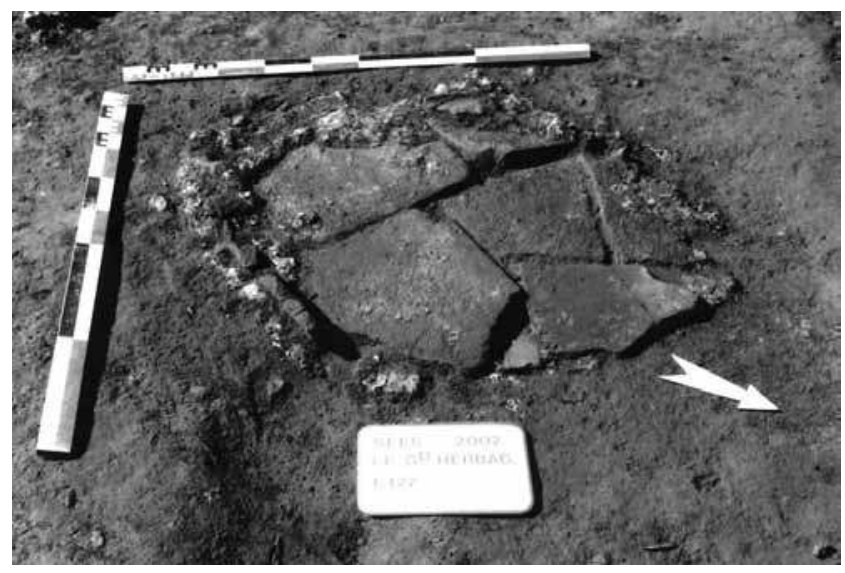

Figure 21: Vue du bac en tuiles F 127.

Figure 21: The F 127 tile-lined tank.

\section{Les productions d'Argonne}

Les sigillées issues de l'aire domestique comprennent un seul tesson de Gaule centrale (forme Drag 45) contre 52 fragments d'Argonne, avec des formes Chenet 320 (16 exemplaires) dont trois morceaux de panses décorés à la molette (références 2 et 5 de Hübener ${ }^{21}$ ), 7 tessons de Chenet 323 et un individu $323 \mathrm{c}$ archéologiquement complet, un pied de gobelet Chenet 334/338, une anse plate bifide de cruche Chenet $343 / 348$ ou 349. Enfin, un rebord de mortier Chenet 330 doté d'un décor à la molette (casiers) provient sans doute de l'atelier B des Allieux (vers 360). Les oreilles de la tête de lion y ont été rajoutées après démoulage sous la forme de dépressions réalisées à la gouge ${ }^{22}$.

21. La référence 5 est une molette apparentée au type 156 d'Unverzagt.

22. Un exemplaire du même type a été récupéré sur les thermes d'ÉpiaisRhus dans le Val d'Oise (Jobelot et Vermeersch, 1996, p. 152-153). 


\begin{tabular}{|l|l|l|l|l|}
\hline Aire d'habitat & NT & \% NT & NMI & \% NMI \\
\hline Sigillée Centre & 1 & 0,1 & 1 & 1,0 \\
\hline Sigillée Argonne & 52 & 5,3 & 14 & 13,0 \\
\hline Argonne (autres) & 10 & 1,0 & 6 & 5,5 \\
\hline Craquelée bleutée (imitation ?) & 4 & 0,4 & 1 & 1,0 \\
\hline Black-burnished 1 & 5 & 2,0 & 2 & 4,6 \\
\hline Mortiers & 9 & 1,0 & 4 & 3,7 \\
\hline Communes claires & 264 & 26,8 & 16 & 14,3 \\
\hline Communes sombres & 625 & 63,5 & 61 & 56,6 \\
\hline (dont modelée) & $(18)$ & & $(3)$ & \\
\hline Total & 966 & $100 \%$ & 104 & $100 \%$ \\
\hline
\end{tabular}

Black Burnished Ware 1 (BB1) ont été recueillis dans l'aire domestique. Dans le répertoire des formes, les jattes à collerette prédominent et sont comparables aux exemplaires $\mathrm{C}$ de Bayeux (Delacampagne et Dufournier 1993, p. 42), 10 et 11 d'Amiens ou de Martaineville (Tuffreau-Libre et al., 1995, p. 103), ou encore au type 45 de Tyers (Tyers 1996, p. 184). Une assiette à lèvre légèrement infléchie vers l'intérieur complète le corpus.

\section{La céramique commune de l'habitat}

\begin{tabular}{|l|l|l|l|l|}
\hline Cour (secteur réoccupé) & NT & \% NT & NMI & \% NMI \\
\hline Sigillée Centre & 6 & 4,0 & 3 & 8,8 \\
\hline Sigillée Argonne & 21 & 14,0 & 7 & 20,6 \\
\hline Argonne (autre) & $/$ & $/$ & $/$ & $/$ \\
\hline Métallescente & 3 & 2,0 & 1 & 2,9 \\
\hline Mortiers & 3 & 2,0 & 3 & 8,8 \\
\hline Communes claires & 40 & 26,7 & 7 & 20,6 \\
\hline Communes sombres & 77 & 51,3 & 13 & 38,2 \\
\hline Total & 150 & $100 \%$ & 34 & $100 \%$ \\
\hline
\end{tabular}

Létude quantitative du lot de céramiques communes recueillies sur l'habitat du Iv ${ }^{\mathrm{e}}$ siècle démontre que les produits à cuisson réductrice sont majoritaires (70\%) par rapport aux exemplaires à pâte claire. Ces derniers sont caractérisés par des pâtes plus ou moins sableuses de couleur beige clair à beige foncé parfois à cœur gris, plus rarement à pâte blanche ou marron-rouge, avec éventuellement des inclusions de chamotte ou de quartz. Un lot de communes claires et sombres se distingue par sa pâte glauconieuse. Le répertoire des formes comprend des mortiers à bandeau vertical ou oblique, des bols à collerette, des jattes et gobelets à lèvres éversées et deux cruches à rebord en corniche ou en poulie.

Les céramiques à pâte sombre appartiennent à deux lots technologiquement différents ${ }^{23}$.

- Le premier ensemble regroupe des productions soignées

Tableau 2 : Décompte des types de céramiques pour les principaux ensembles du Bas-Empire (NT : nombre de tessons; NMI : nombre minimum d'individus).

Table 2: Summary of ceramic types for the main Low-Empire assemblages (NT: number of shards; NMI: minimal number of individuals).

Les autres productions d'Argonne comprennent des fragments d'une cruche Chenet 345/348 à pâte brun-rouge et surface brune avec décor de bande horizontale blanche. Un autre vase du même type présente une pâte grise assez homogène avec un décor monochrome brun foncé doté d'une bande horizontale et d'un rinceau. Le lot est complété par un fragment de bol à collerette à pâte grise à gris orangé, un fragment de petit mortier Chenet 331 à pâte grise, un rebord de gobelet ovoïde Chenet 334/335 (même pâte) et un bord de gobelet évasé Chenet 342 à pâte grise et surface gris jaunâtre avec décor de deux rangées horizontales de guillochis (Chenet, 1941).

Le décapage de la zone réoccupée de la cour d'origine a livré 21 tessons appartenant exclusivement à des formes Chenet 320 et 324 .

\section{La céramique romano-britannique}

Les productions issues du sud de la Bretagne romaine sont peu représentées sur l'habitat où seulement 5 tessons du type texture très homogène. Les pâtes sont de couleur gris clair à gris bleuté et noire. Les surfaces noires, grises et quelquefois gris bleuté, sont souvent lissées avec des bandes horizontales. Des céramiques comparables ont été mises en évidence dans un contexte de la $1^{\text {re }}$ moitié du IV siècle sur le site de Bretteville-l'Orgueilleuse dans le Calvados (Navarre, 1997, p. 424-427).

Ce premier groupe comprend des formes ouvertes et en particulier des jattes à bandeau large imitées du Chenet 324 . Ce type est présent, par exemple, à Nantes sur le site de l'Hôtel-de-Ville (Pirault, 1997, p. 299). Les jattes et bols à collerette rappellent des produits connus aux $\mathrm{II}^{\mathrm{e}}$ et $\mathrm{III}^{\mathrm{e}}$ siècles; il en est de même pour les écuelles et les coupes à bord rentrant. Les formes hautes fermées sont bien représentées et appartiennent à des pots et gobelets à lèvres infléchies vers l'extérieur et présentant des profils variés : à bandeau, en poulie, carré, triangulaire. Un seul mortier en pâte grise et surface bleutée a été identifié dans le corpus. Enfin, trois fragments de couvercles complètent la documentation avec un individu à la face supérieure lustrée, comparable à un spécimen répertorié à Rezé (Pirault, 1997, p. 303-304). Ce

23. La même répartition des céramiques grises en deux groupes a été observée dans l'Eure (Adrian 2002, p. 175). 


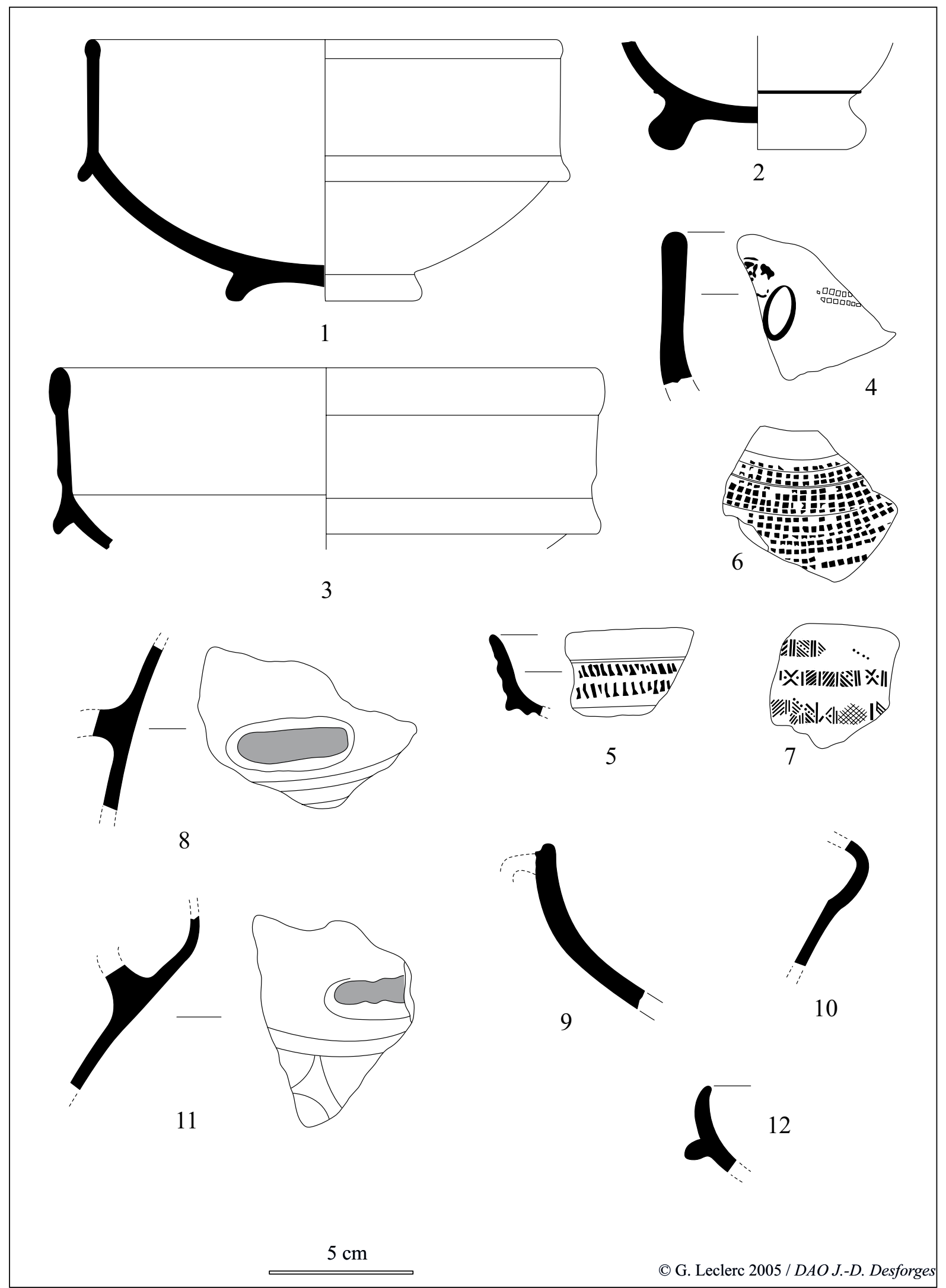

Figure 22 : Habitat du Iv ${ }^{\mathrm{e}}$ siècle, céramique d'Argonne : sigillée (1-7) et autre (8-12).

Figure 22: Argonne ware from $4^{\text {th }}$ century settlement. 


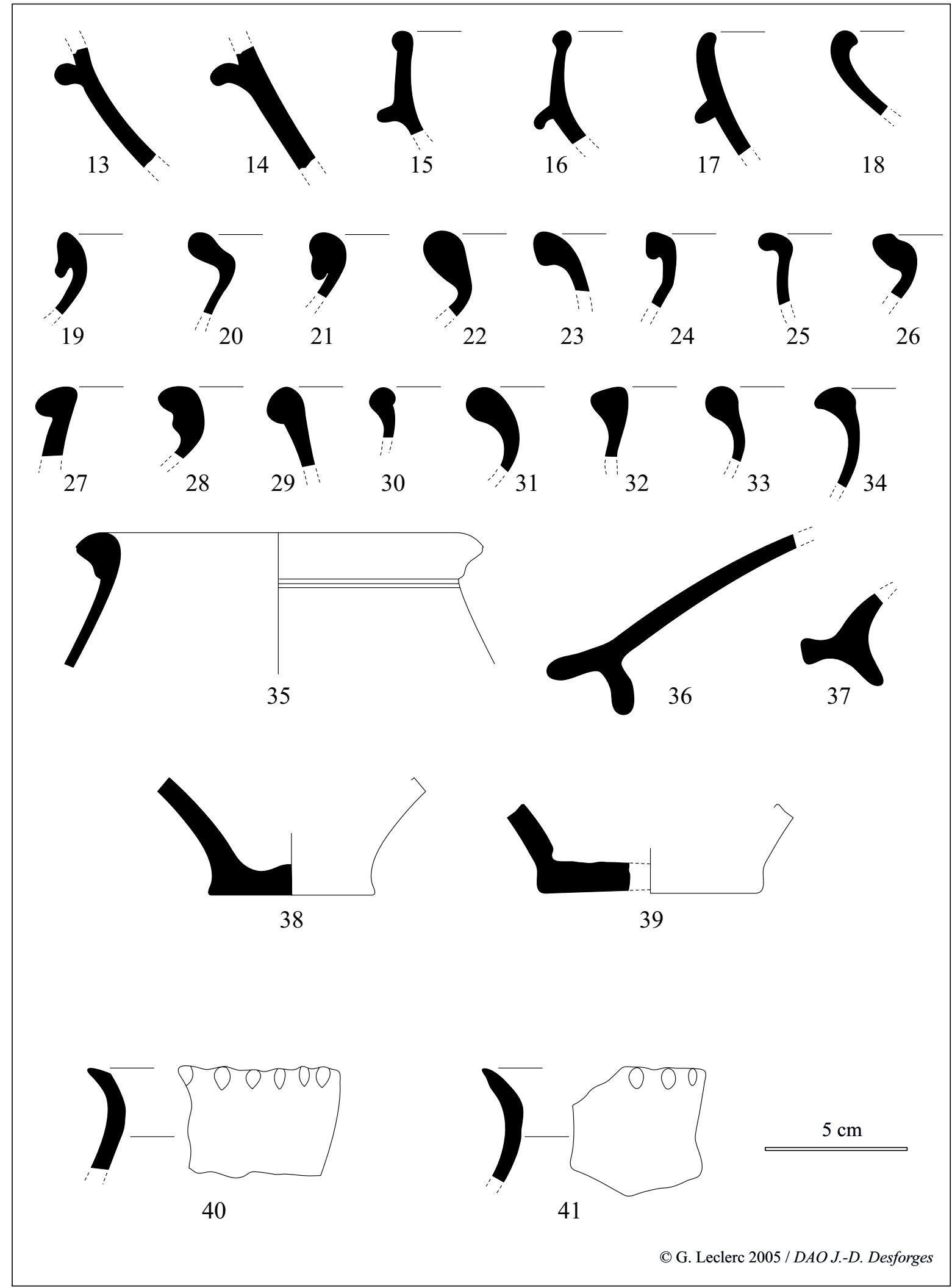

Figure 23 : Habitat du Iv ${ }^{e}$ siècle : «black-burnished 1 » $(13,14)$; céramiques communes sombres $(15-41)$, dont 2 cols à impressions digitées (40-41).

Figure 23: $4^{\text {th }}$ century settlement: black burnished 1 ware and common dark wares (two of them finger-printed). 
premier groupe n'apparaît pas fondamentalement différent des productions classiques du $\mathrm{III}^{\mathrm{e}}$ siècle que ce soit au niveau des pâtes ou des formes.

- Un second lot est constitué de vases à pâtes plus épaisses, quelquefois peu cuites, à texture plus grossière avec généralement des inclusions de quartz blanc ou marron. Les surfaces, majoritairement de couleur grise et parfois rugueuses, ne présentent pas de traces de traitement hormis quelques cas de polissage.

Ce groupe technologique marque une rupture avec les productions habituelles du $\mathrm{III}^{\mathrm{e}}$ siècle et semble représentatif des productions locales ou régionales pour la première moitié $\mathrm{du}$ IV $^{e}$ siècle. Le catalogue des formes privilégie les gobelets à pied étroit et les vases à lèvre éversée au profil arrondi ou triangulaire. Quelques jattes à profil en $S$ inversé et trois vases à bord rentrant complètent ce sous-ensemble où les pots sont sousreprésentés. Que ce soit au niveau des pâtes ou des formes, cette production n'est pas comparable avec les céramiques « rugueuses » du Bassin Parisien qui n’apparaissent qu’à partir du milieu du Iv siècle (Barat, 1993, p. 171-177). Quelques fragments de vases modelés à pâte bioclastique appartiennent à des céramiques de tradition germanique; la pâte en est noire et les tessons proviennent de gobelets dotés d'un rebord éversé à lèvre aiguë décorée d'incisions sur le bord, à rapprocher des formes I 14 et I 17 de Brulet (Brulet, 1990).

\section{La céramique de la fosse $F 130$}

Le comblement de la fosse F 130 a livré 72 fragments de céramique commune dont un seul à cuisson oxydante. La commune sombre y présente des similitudes avec les céramiques recueillies sur l'habitat, avec les deux groupes technologiques répartis, dans les mêmes proportions, entre les productions fines sableuses à surface gris bleuté ou noir $(61 \%$ des communes sombres) et celles de structure plus grossière, souvent dégraissées au quartz et à surface grise (39\%).

Concernant les formes, le premier groupe comprend des coupes à parois fines et à rebord éversé oblique, un bol à collerette, de petits vases à bords droits, en poulie ou à crochet; un seul spécimen est doté d'un rebord aigu rentrant. Au second groupe appartiennent un bol tripode non strié à la base, la partie inférieure d'un vase à fond plat et panse globuleuse et des pots à lèvres carrées ou triangulaires plus ou moins infléchies vers l'extérieur.

\section{SYNTHÈSE}

\section{Le site dans son environnement antique}

Les investigations menées sur le site du Grand-Herbage ont livré l'image d'un établissement agricole sans doute représentatif des occupations rurales antiques de la plaine de Sées. Dans cette micro-région, au vu des données de prospection et des sondages d'évaluation, la hiérarchisation des sites paraît beaucoup plus restreinte que dans d'autres régions comme le Berry où l'éventail typologique des occupations est très large, du petit bâtiment rural jusqu'à la très grande villa au plan complexe (Gandini, 2000). Dans le réseau des sites ruraux antiques, Le Grand-Herbage correspond à un modèle intermédiaire entre la villa palatiale somptuaire et la ferme directement héritée des établissements laténiens. Il s'agit d'un concept associant un habitat en dur pourvu d'un certain confort (chauffage par le sol, murs décorés) et des installations sur poteaux porteurs. La présence dans la cour d'activités agricoles habituellement rejetées à l'extérieur dans les villae italiques témoigne "d'une forte pérennité du fonds indigène " (Gandini, 2000) et " du caractère inachevé de l'évolution vers un modèle romanisé " comme cela a pu être observé en Gaule du nord, par exemple en Picardie (Bayard 1996, p. 169).

À l'exemple du Grand-Herbage, les établissements ruraux du Haut-Empire de la Plaine de Sées se singularisent par la modestie de leur emprise. Dans l'état actuel des données, il n'a été reconnu dans les plaines centrales de l'Orne aucune grande villa de type latifundiaire comme il en existe dans d'autres secteurs du département (Colombiers, Villiers-sous-Mortagne). Les deux établissements fouillés récemment à Ménil-Froger (Ferrette, 2004) et à Marcei (Le Gaillard, 2003, p. 12-16) sur les emprises des autoroutes A 28 et A 88 , à la périphérie $\mathrm{du}$ territoire sagien, ne remettent pas fondamentalement en cause les acquis du Grand-Herbage, même si la morphologie de Marcei est plus élaborée avec une résidence dotée d'une galerie. Les sites recensés appartiennent plutôt à une catégorie d'exploitations moyennes desquelles devaient dépendre d'autres unités de production plus modestes repérées en prospection pédestre. Cette première approche permet de proposer l'hypothèse d'un mode original d'exploitation du sol prenant en compte la qualité agronomique des terrains loessiques nécessitant une moindre surface des fondi pour une production identique. À surface égale, la région de Sées - aux sols riches - pouvait sans doute assurer la subsistance d'un plus grand nombre d'entités agricoles.

Au Iv siècle, la rétraction de l'habitat du Grand-Herbage et son architecture en matériaux périssables marquent une véritable rupture avec la norme romaine, à l'exemple de ce qui a pu être observé dans les régions voisines comme l'Île-de-France et le Nord de la Gaule où " la contraction de la taille des habitats, l'emploi prépondérant des matériaux périssables et l'importance des constructions sur poteaux sont les traits caractéristiques de l'évolution que subissent les établissements ruraux durant l'antiquité tardive " (Ouzoulias, et Van Ossel, 2001, p. 168). "Les réfections 
sont sommaires et trahissent une architecture en régression " (Brulet, 1990). Au Grand-Herbage, les marques de transformation révèlent " une déchéance $[. .$.$] du concept même de$ la villa» (Van Ossel, 1992).

Dans le cadre régional, et en particulier dans le Calvados, les campagnes de fouilles récentes ont validé cette régression architecturale des établissements ruraux après la crise du III $^{\mathrm{e}}$ siècle : c'est le cas à Mondeville "Le Haut SaintMartin " avec des édifices en bois implantés à l'intérieur de bâtiments du Haut-Empire (Renault, 1993, p. 33-35) ou à Bretteville-L'Orgueilleuse " La Corneille », qui présente des petites constructions sans fondations à bâti de bois (Pétorin et Allart, 1996, p. 22).

\section{L'activité économique}

Les données de fouilles ont validé la vocation agricole de l'occupation du Grand-Herbage. Si les espèces de céréales cultivées ne sont pas connues, faute de graines récupérées par exemple dans des fosses de stockage, la pratique de cultures céréalières - en particulier sous le Haut-Empire - est attestée par les constructions mises au jour (greniers aériens et aire de battage). Concernant l'élevage, des informations quantitatives et qualitatives ont pu être acquises par l'analyse des restes fauniques entreprise par Anna Baudry-Dautry (ce vol.). Sous le Haut-Empire, la consommation de viande de bovidés prédomine et les stigmates de découpe sur les os témoignent d'une activité bouchère sur des sujets jeunes élevés pour la viande. Les données archéozoologiques ne permettent pas de quantifier la part de cette production carnée réservée pour l'autoconsommation du domaine et celle sans doute destinée au marché urbain local.

La proximité de la forêt a favorisé la pratique de la chasse et la consommation de viande de cervidés comme le suggèrent les armes en fer (javelines) et quelques restes de faune - os longs et bois de massacre - retrouvés sur le site. L'activité cynégétique paraît toutefois limitée et faiblement complémentaire, de même que la consommation de coquillages marins.

Sous l'Antiquité tardive, l'absence de structures reconnues de stockage des grains suppose un net déclin des activités agricoles avec un ralentissement des cultures au profit de l'élevage comme cela a pu être observé en Bretagne armoricaine (Marguerie et Langouët, 1993, p. 109). Les bovidés restent l'espèce prédominante et confirment les observations effectuées sur d'autres sites ruraux de Normandie.

Des traces discrètes d'artisanat ont été identifiées sur le site, telles que le travail du bois de cervidé et de l'os, attesté par quelques rejets. Des marques de chaufournerie et un lot conséquent d'outils destinés au travail du bois témoignent d'activités autarciques sans doute temporaires ou épisodiques pour la première. Aucune trace de forge ni de résidus ferreux ne signale la présence d'une production métallurgique.

\section{Les circuits commerciaux}

Depuis sa création jusqu'à son abandon définitif, l'établissement du Grand-Herbage bénéficie d'un approvisionnement en produits manufacturés tels que la céramique et les éléments de parure. Les sigillées du centre et de l'est de la Gaule sont présentes de façon significative ainsi que, de manière plus discrète, quelques exemplaires de black-burnished romano-britannique; Sées constitue, dans l'état actuel des données, la limite méridionale en Normandie de l'aire de diffusion de cette production d'outre-Manche.

Les ensembles de céramiques communes sont représentatifs des faciès connus sur les sites ornais comme l'amphore Gauloise 12 par exemple. Ils proviennent sans doute des ateliers chartrains, franciliens ou manceaux (production à couverte bleutée).

Quelques artefacts récupérés dans les niveaux du IV siècle - fibule, céramiques - témoignent d'une influence germanique. Ce fait n'est pas suffisant pour accréditer la thèse d'une présence sur l'établissement de colons originaires de l'Est, même si cette hypothèse ne peut être écartée étant donné qu'en Basse-Normandie des individus anthropologiquement exogènes ont été retrouvés en contextes funéraires (AlducLebagousse et Buchet, 1990, p. 109-113).

L'usage de la monnaie dans les échanges est avérée, même si le numéraire récupéré sur le gisement parait quantitativement peu important, surtout pour le Haut-Empire (fig. 24). Cette constatation peut suggérer que les occupants du GrandHerbage étaient faiblement monétisés. L'abondance relative de monnaies de l'ère constantinienne n'est pas liée à un regain de prospérité de l'établissement au Iv siècle mais plutôt consécutive à la dévaluation du nummus de cuivre ${ }^{24}$.

nombre de

monnaies

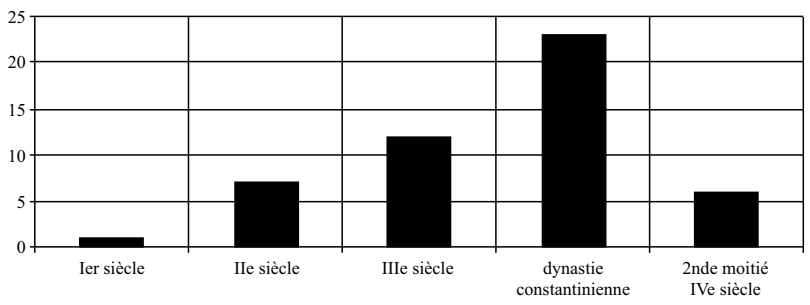

Figure 24 : Sées, Le Grand-Herbage : effectif des monnaies par périodes.

Figure 24: Number of coins, by periods.

24. L'abondance du monnayage de cuivre sous Constantin a affaibli le pouvoir d'achat du nummus qui était 40 fois inférieur à celui de l'époque de Dioclétien. 


\section{Bibliographie}

Adrian, Y.-M., 2002 - La céramique et le petit mobilier domestique du Bas-Empire - haut Moyen Âge (IV -VIII ${ }^{\mathrm{e}}$ siècles) dans la région d'Évreux (Eure) : première approche, Revue Archéologique de l'Ouest, 19, p. 171-218.

Adrian, Y.-M. et LePert, T., 2000 - Nouvelles données sur l'atelier de potiers gallo-romain des " Mares-Jumelles » (Eure), Revue archéologique de l'Ouest, 17, p. 183-197.

Alduc-Le Bagousse, A. et Buchet, L., 1990 - La présence d'étrangers dans la Plaine de Caen ( $\mathrm{IV}^{\mathrm{e}}$ et $\mathrm{v}^{\mathrm{e}}$ siècles), Attila, les influences danubiennes dans l'Ouest de l'Europe, Caen, Publications du Musée de Normandie, 9, 137 p.

BARAT, Y. 1993 - Les céramiques " rugueuses " ou " granuleuses " du Bas-Empire en Île-de-France, Trésors de terre, catalogue d'exposition : Versailles, Paris, Guiry-en-Vexin, 1993-1994, Versailles, Conseil général des Yvelines, Service départemental d'Archéologie, p. 171-177.

BARAT, Y., 1999 - La villa gallo-romaine de Richebourg (Yvelines), Revue archéologique du Centre de la France, 38, p. 125, 144-148.

BAYARD, D., 1996 - La romanisation des campagnes en Picardie à la lumière des fouilles récentes : problèmes d'échelles et de critères, dans Bayard, D. et Collart, J.-L. (dir.), De la ferme indigène à la villa romaine, Actes du $2^{\mathrm{e}}$ colloque de l'Association AGER, Amiens, 1993, Revue archéologique de Picardie, $\mathrm{n}^{\circ}$ spécial 11, p. 157-184.

Baudry, A., 2007 - La faune de l'établissement rural antique de Sées "Le Grand-Herbage "(Orne), Revue archéologique de l'Ouest, 24, p. 191-201.

Besnard-Vauterin, C.-C., 2005 - Une ferme de la fin de l'époque gauloise à Neuville-près-Sées "Les Ruisseaux " (Orne), Revue archéologique de l'Ouest, 22, p. 181-198.

Blaszkiewicz, P. et Churin, T., 1991 - Découverte d'un four de potier à Sées (Orne), Revue archéologique de l'Ouest, 8, p. 117-122.

Brulet, R., 1990 - La Gaule septentrionale au Bas-Empire. Trier (Trèves), Rheinischen Landesmuseums, $431 \mathrm{p}$.

Carpentier, V., Lepaumier, H. et Marcigny, C., 2004 - L'évolution d'un terroir du Néolithique au Moyen Âge à Évreux, Archéopages, 14, p. 24-33.

Chenet, G., 1941 - La céramique gallo-romaine d'Argonne du IV siècle et la terre sigillée décorée à la molette, Mâcon, 191 p., 38 fig.

Courbot, C., 1998 - Un établissement agricole du Haut-Empire à Pluméliau (Morbihan), Revue archéologique de l'Ouest, 15, p. 127-140.

Degbomont, J.-M., 1984 - Hypocaustes, Études et Recherches archéologiques de l'Université de Liège, 17 (2 éd.), 240 p.

Delacampagne, F. et Dufournier, D., 1993 - La céramique BB1 sur le littoral bas-normand : l'exemple de Bayeux. Saxon Symposium, 39, p. 39-47.
Demarest, M., 2007 - Le mobilier métallique du "GrandHerbage " à Sées (Orne), Revue archéologique de l'Ouest, 24, 2007, p. 169-189.

Feller, M., 1991 - Classification et datation des molettes d'Argonne. Problèmes de méthodes, Actes du Congrès de Cognac, Marseille, Société Française pour l'Étude de la Céramique antique en Gaule (SFÉCAG), p. 161-169.

Ferrette, R., 2004 - Autoroute A 28 nord; Ménil-Froger, Le petit Parc (Orne), DFS de fouille préventive, Caen, INRAP/SRA de Basse-Normandie, $200 \mathrm{p}$.

Feugère, M., 1985 - Les fibules en Gaule méridionale (de la Conquête à la fin du v siècle apr. J-C), Revue archéologique de Narbonnaise, suppl. 17, 509 p.

Gandini, C., 2000 - Le Berry antique, Revue archéologique $d u$ Centre de la France, 21 ${ }^{\mathrm{e}}$ suppl., p. 61-73.

GuILlier, G., 1997 - La production céramique du Haut-Empire de l'officine de La Bosse (Sarthe), Actes du Congrès du Mans, Marseille, Société Française pour l'Étude de la Céramique antique en Gaule (SFÉCAG), p. 239-254.

Jobelot, N. et Vermeersch, D., 1996 - Céramiques gallo-romaines $d u$ Val-d'Oise, Pontoise, Service départemental d'Archéologie du Val-d'Oise, 220 p.

LeClerc, G., 1997 - L'aqueduc gallo-romain de Sées (Orne), Document Final de Synthèse, Caen, Service Régional de l'Archéologie de Basse-Normandie, 85 p.

LECLERC, G., 1998 - Étude d'une adduction d'eau gallo-romaine à Sées (Orne), Document Final de Synthèse, Caen, Service Régional de l'Archéologie de Basse-Normandie, 53 p.

LeClerc, G., 1999 - Prospection thématique, Sées (Orne) : Le Crochet, Le Hamel, Le Grand Herbage, Document Final de Synthèse, Caen, Service Régional de l'Archéologie de BasseNormandie, $129 \mathrm{p}$.

Le Gaillard, L., 2003 - Autoroute A 88, section Argentan nord - Sées, DFS de diagnostic archéologique, Caen, INRAP/SRA de Basse-Normandie, p. 12-16.

Marguerie, D. et Langouët, L., 1993 - Le déclin des activités agricoles au Bas-Empire en Armorique, corrélation des données palynologiques et archéozoologiques, Les Dossiers du CeRAA, 21, p. 109-113.

Ménez, Y., 1985 - Les céramiques fumigées de l'ouest de la Gaule, Cahiers de Quimper antique, $\mathrm{n}^{\circ} 2,125$ p., $44 \mathrm{pl}$.

Ménez, Y., 1989 - Les céramiques fumigées "terra nigra " du Bourbonnais, Revue archéologique du Centre de la France, 282, p. 117-178.

Navarre, N., 1997 - La céramique gallo-romaine en plaine de Caen, des Antonins au Bas-Empire : trois exemples de lots céramiques issus de la fouille de La Corneille-Nord (Brettevillel'Orgueilleuse, Calvados), Actes du Congrès du Mans, Marseille, Société Française pour l'Étude de la Céramique antique en Gaule (SFÉCAG), p. 407-430. 
Oswald, F., 1983 - Index des estampilles sur sigillée, Revue archéologique Sites, Hors série $\mathrm{n}^{\circ} 21,428 \mathrm{p}$.

Ouzoulias, P. et Van Ossel, P., 2001 - Dynamiques du peuplement et formes de l'habitat tardif : le cas de l'île-de-France, in Ouzoulias, P. et al. (dir.), Les campagnes de la Gaule à la fin de l'Antiquité (IVe colloque de l'Association AGER, 1998), Antibes, éditions APDCA, p. 147-172.

Paez-Rezende, L., 1997 - Incarville (Eure), "Les Prés ». Échangeur RN 154/A 13, Document Final de Synthèse, volume 1, Rouen, Service Régional de l'Archéologie de Haute-Normandie, p. 35-37.

Pannetier, V., 1996 - Les parties agricoles des villae dans le nord de la Gaule ( $\mathrm{I}^{\mathrm{er}}$ au III $^{\mathrm{e}}$ siècle apr. J.-C.), Revue du Nord, 78 (n 318), p. 163-175.

Pétorin, N. et Allart, E., 1996 - Bretteville-L'Orgueilleuse, La Corneille-nord, Bilan scientifique régional, DRAC de BasseNormandie/Service régional de l'Archéologie, p. 22.

Philippe, J., 1999 - Les fibules en Seine-et-Marne du $1^{\text {er }}$ siècle av. J.-C. au ve siècle apr. J.-C., Mémoires archéologiques de Seineet-Marne, 1, Nemours, Service départemental d'Archéologie de Seine-et-Marne, 234 p.
Pirault, L., 1997 - La céramique tardive à la fin du Bas-Empire à Nantes, Saint-Herblain et Rezé (Loire-Atlantique) - État des connaissances, Actes du Congrès du Mans, Marseille, Société Française pour l'Étude de la Céramique Antique en Gaule (SFÉCAG), p. 293-307.

Renault, V., 1993 - Mondeville (14), Le Haut Saint-Martin, Bilan scientifique régional, Caen, DRAC de Basse-Normandiel Service régional de l'Archéologie, p. 33-35.

SANTrot, J. et M-H., 1979 - Céramiques communes gallo-romaines d'Aquitaine, Paris, CNRS, 262 p. + 147 pl.

Tufreau-Libre, M., Mossmann-Bouquillon, A. et Symonds, R. P., 1995 - La céramique dite Black-Burnished dans le Nord de la France, Actes du Congrès de Rouen, Marseille, Société Française pour l'Étude de la Céramique antique en Gaule (SFÉCAG), p. 91-112.

Tyers, P., 1996 - Romano-British coarse wares, Roman Pottery in Britain, 12, p. 182-189.

VAN Ossel, P., 1992 - Établissements ruraux de l'antiquité tardive dans le nord de la Gaule, 51 ${ }^{\mathrm{e}}$ supplément à Gallia, éditions du CNRS, Paris, p. 125-127. 
